\title{
ESTÁNDAR DE MOTIVACIÓN O FUNDAMENTACIÓN EN EL RECHAZO DE LICENCIAS MÉDICAS POR CAUSALES DE ORDEN MÉDICO: UN ESTUDIO JURISPRUDENCIAL
}

\author{
STANDARD OF MOTIVATION OR JUSTIFICATION IN THE \\ REJECTION OF SICK LEAVES BY CAUSAL MEDICAL ORDER: A \\ JURISPRUDENTIAL STUDY
}

CLAUDIO OSSES SILVA*

\section{RESUMEN}

Muchas licencias médicas son rechazadas por causales de orden médico sin expresar suficientemente las razones para ello. Varios recursos de protección se han presentado pretendiendo declarar arbitrarios e ilegales estos pronunciamientos, con dispares resultados, sentando criterios contradictorios entre sí, aun en una misma Corte de Apelaciones. A través del estudio de la jurisprudencia judicial y administrativa, se pretende establecer un estándar básico para fundamentar o motivar estos rechazos, a fin de garantizar el respeto de los derechos fundamentales de la población enferma.

Palabras Clave: Licencia médica; pronunciamiento; rechazo; motivación.

\footnotetext{
*Abogado, Universidad de Concepción, Magíster en Derecho del Trabajo y Previsión Social, Universidad de Concepción. Correo electrónico: c.m.osses.s@gmail.com.

Artículo recibido el 2 de marzo de 2019 y aceptado para su publicación el 10 de junio de 2019.
} 


\section{ABSTRACT}

Many sick leaves are rejected by causal medical order without expressing sufficiently the reasons to do so. Protection remedies have submitted pretending to declare illegal and arbitrary these pronouncements, with disparate results, laying contradictory criteria with each other, even in a Court of Appeals. Through the study of judicial and administrative jurisprudence, it is intended to establish a basic standard to explain or motivate these rejections, in order to ensure respect for the fundamental rights of the sick people.

Keywords: Sick leave; pronouncement; rejection; motivation.

\section{PRESENTACIÓN}

Es una realidad incuestionable que buena parte de la población laboral sufrirá a lo largo de su vida alguna enfermedad que le incapacitará, temporal o definitivamente, para prestar sus servicios. Ello ha impulsado la creación de un conjunto de herramientas para permitir justificar una ausencia laboral y suplir la pérdida de ingresos que, en consecuencia, tendrá una persona. Entre aquéllas, está la más básica e imprescindible de todas: la licencia médica.

Pero su otorgamiento ha provocado varios problemas. El más importante, por sus efectos, consiste en su rechazo por causales de orden médico que, en el parecer de los agraviados, carecen de todo fundamento, provocando así una ingente cantidad de recursos de protección deducidos.

Los interesados alegan que los pronunciamientos emitidos por las Instituciones de Salud Previsional (en adelante, ISAPRE), las Comisiones de Medicina Preventiva e Invalidez (o COMPIN) y la Superintendencia de Seguridad Social (o SUSESo), no satisfacen un estándar mínimo de fundamentación o motivación; que las razones dadas son ininteligibles, insuficientes o lacónicas; y que, por lo mismo, son actos arbitrarios e ilegales, privando a los recurrentes de su dominio sobre prestaciones de Seguridad Social.

En este estudio pretendemos sentar las bases de un estándar de fundamentación o motivación de los rechazos de orden médico, a fin de que las partes interesadas (léase trabajadores, empleadores y quienes deben emitir los pronunciamientos) puedan, o ejercer con mayor éxito las acciones 
tendientes a obtener un pronunciamiento favorable, o elevar la calidad de sus decisiones.

Con este fin, hemos determinado un conjunto de aspectos problemáticos que dicen relación con la fundamentación o motivación de los rechazos. Luego, reunimos jurisprudencia judicial y administrativa, ${ }^{1}$ extrajimos sus partes más valiosas y las reunimos según los aspectos tenidos en cuenta; notando, entre otras cosas, la discordante y contradictoria jurisprudencia (sobre todo judicial) que existe en nuestro país.

Pero antes, debemos realizar una pequeña explicación.

\section{LAS LICENCIASMÉDICAS, SUTRAMITACIÓN, PRONUNCIAMIENTO E IMPUGNACIÓN}

\section{Definición de la licencia médica}

Contrario a lo que pudiera pensarse, la licencia médica presenta más de una definición en nuestro Derecho. Por un lado, es "el derecho que tiene el trabajador de ausentarse o reducir su jornada de trabajo, durante un determinado lapso de tiempo, en cumplimiento de una indicación profesional certificada por un médico-cirujano, cirujano-dentista o matrona, (...) según corresponda, reconocida por su empleador en su caso, y autorizada por la Comisión de Medicina Preventiva e Invalidez, en adelante 'COMPIN', de la Secretaría Regional Ministerial de Salud, en adelante 'SEREMI', que corresponda o Institución de Salud Previsional según corresponda, durante cuya vigencia podrá gozar de subsidio de incapacidad laboral con cargo a la entidad de previsión, institución o fondo especial respectivo, o de la remuneración regular de su trabajo o de ambas en la proporción que corresponda". ${ }^{2}$

\footnotetext{
1 En honor a la verdad, todos los dictámenes de la SUSESO aquí reunidos resuelven recursos administrativos deducidos contra pronunciamientos negativos de las entidades encargadas de autorizar las licencias médicas, y muchas de las sentencias incorporadas al estudio se pronuncian sobre la legalidad de aquéllos. Pero la inmensa mayoría de la jurisprudencia administrativa (sea la de los dictámenes o la contenida en las sentencias judiciales) comparte el mismo pecado original que los pronunciamientos emitidos por las ISAPRE, la COMPIN o la Unidad de Licencias Médicas: la falta o insuficiencia de fundamentación-motivación.

Varios pronunciamientos se limitan a señalar, como causal de rechazo, que el reposo es injustificado o prolongado, sin dar mayores razones que un par de palabras o una referencia a un par de artículos reglamentarios. Y muchos de los dictámenes de la SUSESO, lisa y llanamente, transcriben el texto de los pronunciamientos originales, haciéndolos suyos. Todo ello nos permite emplear, como base de este estudio, tales dictámenes y sentencias judiciales.
}

2 Artículo $1^{\circ}$ Decreto $N^{\circ} 3,1984$. 
Y por el otro, es "un acto médico administrativo en el que intervienen el trabajador, el profesional que certifica, la COMPIN o ISAPRE competente, el empleador y la entidad previsional o la Caja de Compensación de Asignación Familiar, en su caso. Se materializará en un formulario especial, impreso en papel o a través de documentos electrónicos, que registrará todas las certificaciones, resoluciones y autorizaciones que procedan y cuyo texto será determinado por el Ministerio de Salud". ${ }^{3}$

Atendida esta cualidad, y para los efectos de este artículo, entenderemos por "licencia médica" al documento sometido al procedimiento regulado por el Reglamento ${ }^{4}$ a fin de que la entidad que deba resolver sobre ella emita un pronunciamiento positivo o negativo.

\section{Emisión de la licencia médica, Guías Clínicas Referenciales y} procedimiento de tramitación de aquélla

Como se desprende de la primera definición transcrita, sólo un médicocirujano, cirujano-dentista o matrona puede emitir una licencia médica. Pero quienquiera que la otorgue, deberá ceñirse a lo que la lex artis médica les enseña.

Según la Corte Suprema, ella "está constituida por el conjunto de principios y normas técnicas cuyo dominio es exigido a cuantos ejercen la actividad" (considerando undécimo). ${ }^{5}$ GARRIDO dice, por su parte y en el orden penal, que este canon constituye "el conjunto de reglas que norman el ejercicio de la actividad curativa, tanto en relación a los procedimientos que deben emplearse como a los resguardos y garantías que han de tenerse". ${ }^{6}$ Y Politoff, Matus y Ramírez agregan que el profesional, conforme a esta lex artis médica, debe seguir "los procedimientos médicos enseñados en las Facultades de Medicina, descritos en la bibliografía existente o en las instrucciones del Servicio Nacional de Salud, etc., que sean los adecuados para el diagnóstico y tratamiento de la enfermedad de que se trate". ${ }^{7}$

Aunque la lex artis médica demanda que el profesional realice una

\footnotetext{
3 Artículo $5^{\circ}$ inciso $1^{\circ}$ Decreto $N^{\circ} 3,1984$.

4 Decreto $N^{\circ} 3,1984$. Toda referencia al "Reglamento", se entenderá hecha al Decreto en cuestión.

5 Corte Suprema, 25 de abril de 2017, rol N 38151-2016.

6 Garrido Montt, Mario, Derecho Penal. Parte especial, Editorial Jurídica de Chile, Santiago, 2010, T. III, $4^{\mathrm{a}}$ edición actualizada, p. 181.

7 Politoff L., Sergio; Matus A., Jean Pierre; Ramírez G, María Cecilia, Lecciones de Derecho Penal chileno. Parte especial, Editorial Jurídica de Chile, Santiago, 2005, 2a edición, p. 121.
} 
serie de procedimientos, exámenes e informes en el ejercicio de su labor, nuestra actual regulación ha impuesto, para ciertas patologías, la práctica de exámenes, la elaboración de informes y el acompañamiento de antecedentes, todos ellos preestablecidos, en virtud de las denominadas "Guías Clínicas Referenciales Relativas a Exámenes, Informes y Antecedentes". ${ }^{8}$

El Gobierno, a fin de justificar su existencia, expuso que intentan "evitar la arbitrariedad en el análisis y resolución de las licencias médicas en revisión", 9 y que pretenden "estandarizar los criterios bajo los cuales se resuelva en torno a estas materias". ${ }^{10}$ Así, por ejemplo, para la cervicalgia, ellas no exigen requisito alguno para la emisión de la licencia, siempre que sea la primera y el reposo prescrito no exceda de cinco días. Y para las patologías mentales, las reglas son muchísimo más estrictas, según si el reposo es parcial o total, o si excede de tantos días. Además, de acuerdo con el artículo $4^{\circ}$ del Decreto que las aprobó, ellas son obligatorias, al decir que los exámenes, informes y antecedentes que enuncia deberán respaldar la emisión de las licencias médicas.

De ellas podemos sostener que, primero, pretenden normalizar no solo la emisión de licencias médicas por ciertas patologías, sino que también la duración del reposo prescrito; y segundo, versan sobre las enfermedades de mayor ocurrencia en la población económicamente activa del país. ${ }^{11}$

Una vez expedida, la licencia se someterá a un procedimiento para su autorización, modificación o rechazo, regulado por el Reglamento. Éste permite, en su artículo 21, a las ISAPRE, la COMPIN y la Unidad de Licencias Médicas, adoptar un conjunto de medidas denominadas "para mejor resolver" o "peritajes"; entre las cuales está el practicar o solicitar nuevos exámenes o interconsultas, ${ }^{12}$ conocido también como "peritaje médico". ${ }^{13}$

\footnotetext{
8 Decreto $N^{\circ}$ 7, 2013, dictado en virtud de lo dispuesto en el artículo $4^{\circ}$ de la Ley $N^{\circ} 20.585,2012$.

9 Biblioteca del Congreso Nacional, "Historia de la Ley No 20.585, Sobre Otorgamiento y Uso de Licencias Médicas”, documento pdf. disponible en línea: https:/www.bcn.cl/historiadelaley/ fileadmin/file_ley/4426/Pdf/Dossier/HLD_4426_dossierd10ee3d1e00de59cfdd6070e831cc33d. pdf, (consultado al 30 de mayo de 2019), $\overline{\text { p. }} 18 \overline{1}$

${ }^{10}$ Biblioteca del Congreso Nacional, cit. (n. 9), p. 181

11 Véase al respecto: Superintendencia de Seguridad Social, "Estadísticas nacionales de LM y SIL 2017", documento disponible en línea: https:/www.suseso.cl/608/w3-article-577871.html (visitado al 30 de mayo de 2019).

${ }^{12}$ Artículo 21 inciso $1^{\circ}$ letra a), Decreto $N^{\circ} 3,1984$.

${ }^{13}$ Con todo, el artículo $3^{\circ}$ del Decreto $\mathrm{N}^{\mathrm{o}} 7,2013$, exige que debe adoptarse alguna de las medidas para mejor resolver que enuncia, tratándose de pacientes que tengan indicación de reposo continuo, a contar de la tercera licencia médica.
} 
El pronunciamiento deberá emitirse dentro de un determinado plazo, el cual dependerá según si quien debe resolver es o no una ISAPRE. En el primer supuesto, dentro del plazo fatal de tres días hábiles, contados desde la fecha de presentación y recepción conforme en sus oficinas, de la respectiva licencia. Y en el segundo, el plazo, por regla general, es de siete días hábiles, contados desde que el respectivo formulario sea recibido en las oficinas de la entidad correspondiente. ${ }^{14}$

\section{Pronunciamiento, causales de rechazo de orden médico y procedimientos impugnatorios}

El artículo 16 del Reglamento es muy claro al establecer que quien debe pronunciarse sobre la licencia puede autorizarla, rechazarla, ampliarla o reducirla. Por convencionalismo, las causales de rechazo han sido reunidas en dos grupos: las de orden jurídico-administrativo y las de orden médico. Las primeras obedecen a criterios legales o reglamentarios, tales como que el paciente no es trabajador (dependiente o independiente) o que el formulario de licencia médica fue presentado para su tramitación fuera del plazo reglamentario. ${ }^{15} \mathrm{Y}$ las segundas -que no están reguladas de modo expreso en nuestro Derecho- se sustentan en razones médicas, comprendiéndose aquí al reposo injustificado, el prolongado y la salud irrecuperable, los que pasaremos a ver de inmediato.

El reposo se tiene por injustificado si, tanto de los antecedentes tenidos a la vista o que se obtengan en virtud del ejercicio de un peritaje, como de lo previsto por la lex artis médica, no se logra acreditar la existencia de la enfermedad o la necesidad del reposo prescrito. Eventualmente, si la injustificación es evidente (entendiéndose que la hay cuando existe ausencia de una patología que produzca incapacidad laboral temporal por el período y la extensión del reposo prescrito), ${ }^{16}$ se seguirá un procedimiento administrativo tendiente a la sanción del profesional tratante. ${ }^{17}$

El reposo es prolongado si, según los mismos antecedentes y praxis, se estima que excede al necesario para la recuperación del trabajador.

\footnotetext{
${ }^{14}$ Todo ello según los artículos 24 del Decreto $N^{\circ} 3,1984$, y 196 inciso $2^{\circ}$ del Decreto con Fuerza de Ley $\mathrm{N}^{\circ} 1,2006$.

${ }^{15}$ Estas causales están reguladas, por lo general, por el artículo 55 del Decreto $\mathrm{N}^{\circ} 3,1984$.

${ }^{16}$ Artículo $5^{\circ}$ inciso $4^{\circ}$ de la Ley $\mathrm{N}^{\circ} 20.581,2012$.

${ }^{17}$ Regulado en los artículo $5^{\circ}$ y siguientes de la Ley N 20.581, 2012.
} 
Y existe salud irrecuperable cuando hay una "enfermedad o lesión de carácter permanente que puede evolucionar hacia una fase terminal, determinando algún grado de incapacidad, que según su ponderación y régimen previsional puede dar lugar a una indemnización o a una pensión de invalidez parcial o total, según lo dictamine la Comisión Médica correspondiente". ${ }^{18}$ Sobre esta causal, la SuSESo ha entendido que "existen patologías crónicas (irrecuperables) que permiten trabajar, pero que cada cierto tiempo producen una incapacidad temporal para el trabajador (diabetes, insuficiencia renal en diálisis, hemofilia, etc.) y que, no obstante ser permanentes, podrán servir de fundamento a una licencia médica que prescriba un periodo de reposo a fin de permitir al trabajador, mediante el tratamiento médico adecuado, recuperar su capacidad de trabajo y volver a sus labores habituales". ${ }^{19}$ También dijo que "hay que tener presente que no basta que la patología tenga una naturaleza crónica o irrecuperable para rechazar la licencia médica, debiendo analizarse en cada caso, si al término del reposo la persona va estar o no en condiciones de reintegrarse al trabajo. Existiendo la posibilidad de reintegro laboral, la licencia debe ser autorizada" (las cursivas son nuestras). ${ }^{20}$

Lo recién transcrito morigera bastante lo que debemos entender por salud irrecuperable, pues impide que la sola existencia de una enfermedad crónica o irrecuperable imponga rechazar una licencia médica. Pasa entonces a ser importante, para determinar la existencia o no de irrecuperabilidad, si hay imposibilidad del trabajador enfermo para volver a laborar con su capacidad residual.

Si la licencia médica es rechazada o reducida, la parte agraviada puede, si está afiliado a FONASA, ejercer los recursos administrativos que la ley contempla. ${ }^{21} \mathrm{Si}$ estuviere afiliado a una ISAPRE, puede reclamar ante la COMPIN correspondiente, en la forma que el Reglamento estipula; ${ }^{22}$ sin perjuicio de la obligación que la misma ISAPRE tiene de remitir los antecedentes a la respectiva compin, a fin de que ésta confirme o rechace el pronunciamiento emitido. ${ }^{23}$ Pero solo si el agraviado afiliado a una ISAPRE

\footnotetext{
${ }^{18}$ Circular B10/N 15 , Subsecretaría de Salud Pública, 13 de julio de 2018, punto I.3.

${ }^{19}$ Circular $\mathrm{N}^{\circ} 1588,1997$, punto B.

${ }^{20}$ Circular $\mathrm{N}^{\circ} 2067,2003$, punto A. c).

${ }^{21}$ Ley $\mathrm{N}^{\circ} 19.880,2003$.

${ }^{22}$ Artículos 39 y siguientes del Decreto $\mathrm{N}^{\circ} 3,1984$.

${ }^{23}$ Artículo $3^{\circ}$ inciso $3^{\circ}$ de la Ley $N^{\circ} 20.585,2012$.
} 
recurrió dentro de plazo ante la COMPIN correspondiente, la SUSESO podrá conocer de la apelación que deduzca contra la resolución que la señalada Comisión emitiere.

\section{LAMOTIVACIÓNOFUNDAMENTACIÓNDELPRONUNCIAMIENTO. UNA PEQUEÑA EXPLICACIÓN}

Rechazar una licencia médica requiere esgrimir razones, no solo por las consecuencias prácticas que acarrea tanto para el trabajador como para terceros, sino también, porque existe una disposición expresa en tal sentido. En efecto, el Reglamento estatuye, en el aludido artículo 16, que "se dejará constancia de la resolución o pronunciamiento respectivo, con los fundamentos tenidos a la vista para adoptar la medida, en el formulario digital o de papel de la respectiva licencia".

Si quien tiene que emitir el pronunciamiento (o resolver un recurso o reclamación) es un órgano de la Administración del Estado, debe, además, ceñirse a lo que disponen los artículos 11 inciso $2^{\circ}$ y 41 incisos $4^{\circ}$ y final, de la Ley $\mathrm{N}^{\circ} 19.880$, de 2003. Estas reglas consagran lo que el Derecho Administrativo ha denominado como motivación ofundamentación del acto administrativo. Veamos, entonces, en qué consiste ello.

CORDERo enseña que los actos administrativos deben tener motivos y causa, siendo los primeros "la razón de ser, el fundamento, o si se quiere la causa impulsiva"; ${ }^{24}$ y la segunda no es otra que la causa finalis, y "que la mayoría hace radicar en la adecuación del contenido del acto a los fines que persigue". ${ }^{25}$ Según Celis, el motivo es "el antecedente o fundamento fáctico que justifica la emisión del acto administrativo". ${ }^{26}$ Y para MoRAGA, la motivación es la explicitación del motivo de hecho y de los fundamentos de derecho que justifican el acto administrativo. ${ }^{27}$

\footnotetext{
${ }^{24}$ Cordero Vega, Luis, Lecciones de Derecho Administrativo, Thomson Reuters, Santiago, 2015, ${ }^{\mathrm{a}}$ ed. corregida, p. 263.

${ }^{25}$ Cordero Vega, cit. (n. 24), p. 263.

${ }^{26}$ Celis Danzinger, Gabriel, Curso de Derecho Administrativo, Thomson Reuters - PuntoLex, Santiago, 2010, T. I, p. 352.

${ }^{27}$ Moraga Klenner, Claudio, "Notas al procedimiento administrativo y la doctrina chilena", en Pantoja Bauzá, R. (coord.), Derecho Administrativo. 150 años de doctrina, Editorial Jurídica de Chile, Santiago, 2009, p. 349.
} 
En el parecer de Bermúdez, motivo y causa son lo mismo. ${ }^{28}$ Según él, el motivo es "la razón que justifica casa acto administrativo emanado de la Administración Pública; ${ }^{29}$ y la motivación "consiste en la exteriorización de las razones que han llevado a la Administración Pública a dictar un acto". ${ }^{30}$ Más adelante añade que la motivación obliga a tener en cuenta lo siguiente: la carga de la motivación corresponde a la Administración, o sea, es ella quien debe exponer las razones de su decisión; aunque, en su parecer, se cumpliría esta exigencia haciendo un desarrollo sucinto o resumido de las razones del acto; ${ }^{31}$ debe realizarse mediante referencia a hechos y fundamentos de Derecho; ${ }^{32}$ y debe contar con razones de fondo que demuestren que la decisión no se funda en la sola voluntariedad de quien la adopta. ${ }^{33}$

Sото entiende a la "fundamentación" como "la exposición formal y explícita de la justificación de la decisión. Es decir, la expresión formal de las atribuciones normativas que le permiten a un sujeto-órgano dictar un acto administrativo, de los antecedentes de hecho y de las razones que dan justificación lógica-racional de la decisión que se adopta, para satisfacer una determinada necesidad pública". ${ }^{34}$

Y GoRDILlo, quien prefiere emplear el término "fundamentación", sostiene que es "una declaración de cuáles son las circunstancias de hecho y de derecho que han llevado a su emanación, o sea sus motivos o presupuestos; es la exposición y argumentación fáctica y jurídica con que la administración debe sostener la legitimidad y oportunidad de la decisión tomada". ${ }^{35}$

Como podemos observar, e independiente de los términos empleados o preferidos por unos u otros autores ${ }^{36}$ existe un consenso respecto a que los actos administrativos deben expresar las razones fácticas y jurídicas

${ }^{28}$ Bermúdez Soto, Jorge, Derecho Administrativo general, Thomson Reuters, Santiago, 2014, $3^{\mathrm{a}}$ ed. actualizada, p. 149.

${ }^{29}$ Bermúdez, cit. (n. 28), p. 149.

${ }^{30}$ BERMÚDEZ, cit. (n. 28), p. 151.

${ }^{31}$ BermúdeZ, cit. (n. 28), p. 151.

32 Bermúdez, cit. (n. 28), p. 152.

${ }^{33}$ Bermú́DeZ, cit. (n. 28), p. 152.

${ }^{34}$ Sото KLoss, Eduardo, Derecho Administrativo. Temas fundamentales, Abeledo Perrot LegalPublishing, Santiago, 2012, $3^{\text {a }}$ ed. actualizada, p. 430.

${ }^{35}$ Gordillo, Agustín, Tratado de Derecho Administrativo, Fundación de Derecho Administrativo, Buenos Aires, 2011, $10^{\mathrm{a}}$ edición, T. 3, p. X-15.

${ }^{36}$ Sin embargo, hay que sostener que, respecto de los pronunciamientos emitidos por las ISAPRE, sería preferible utilizar la expresión "fundamentación". 
que permiten sustentar la decisión adoptada. BERMÚDEZ recalca que es la administración quien lleva la carga de motivar sus actos, criterio que, dicho sea de paso, se ajusta a la regla general de fundamentación que AleXY propone: "todo hablante debe, cuando se le pide, fundamentar lo que afirme, a no ser que pueda dar razones que justifiquen el rechazar una fundamentación"; 37 aunque, como recuerda ATIENZA, sólo puede cumplirse de manera aproximada. ${ }^{38}$

Sin embargo, BERMúdEz afirma que basta una exposición sucinta, debido a que el legislador no ha exigido señalar todas las razones..$^{39}$ Aunque es cierto que la ley no está redactada en términos de demandar ese estándar, no es posible aceptar que, por ese solo hecho, se admita lo postulado por este autor sin más.

A pesar de la ausencia de reglas pormenorizadas sobre cómo la Administración debe motivar un rechazo de una licencia médica por motivos médicos, podemos extraer ciertos criterios de nuestra regulación y de la doctrina. Por un lado, la SUSESO exige (en forma indirecta) que los pronunciamientos deben bastarse a sí mismos, sin añadir más sobre las causales objeto de este estudio; ${ }^{40}$ y que, además, debe indicarse el fundamento de la aplicación de la causal. ${ }^{41}$

Por el otro, según el inciso final del artículo 41 de la Ley $N^{\circ} 19.880$, de 2003, se puede motivar un acto administrativo cuando se incorporen a él la aceptación de informes o dictámenes. Se comprenden aquí los peritajes médicos. Esto permite que la incorporación (del texto) de un peritaje aceptado por la Administración, pueda constituir motivación para el pronunciamiento.

$\mathrm{Y}$ un problema frecuente versa sobre aquellos actos administrativos que dan como motivos expresiones cliché o fórmulas de estilo, como lo son las "necesidades del servicio", el "interés público" o la "seguridad nacional". Tanto Soто como Gordillo han dicho que su uso no cumple los requisitos de una motivación válida. ${ }^{42}$ Es más, podemos afirmar que su recurso es apelar a la nada misma: no se puede extraer información valiosa

\footnotetext{
${ }^{37}$ AleXy, Robert, Teoría de la argumentación jurídica. La teoría del discurso racional como teoría de la fundamentación jurídica, Palestra, Lima, 2016, p. 271.

38 Atienza, Manuel, Las razones de Derecho. Teorías de la argumentación jurídica, Universidad Nacional Autónoma de México, Instituto de Investigaciones Jurídicas, México, 2017, p. 158.

${ }^{39}$ Bermúdez, cit. (n. 28), p. 151.

${ }^{40}$ Circular $N^{\circ} 2067,2003$, punto I.

${ }^{41}$ Circular $\mathrm{N}^{\circ}$ 2067, 2003, punto I.3.q).

${ }^{42}$ Soto, cit. (n. 34), p. 431; Gordillo, cit. (n. 35), p. X-13.
} 
para poder comprender por qué se emite un acto administrativo. GoRDILLo llega al extremo de aseverar que la mención del "relato del expediente" (o sea, escribir que a fojas tanto se hizo tal o cual cosa), tampoco agrega a la fundamentación..$^{43} \mathrm{El}$ mismo autor arguye que, si se emplean tales frases, se deberá "explicar clara y acabada, exhaustivamente, cuáles son los hechos que la administración considera que están probados, cuál es la prueba que a su juicio lo sustenta, qué valoración reciben dichas pruebas, qué relación existe entre tales hechos y lo que el acto dispone, qué normas concretas son las que se aplican al caso (no bastando, según quedó dicho, la genérica invocación de una ley) y por qué se las aplica, etc.". ${ }^{44}$ La posibilidad de recurrir a frases cliché o vacías está incluso prohibida por algunas legislaciones extranjeras. ${ }^{45}$

A modo de término de este apartado, la Superintendencia de Salud ha establecido para las ISAPRE una regla muy clara para fundamentar los rechazos por orden médico: "La resolución que se pronuncie sobre la licencia debe ser fundada. Dicha fundamentación debe ser clara, explícita y de fácil comprensión para el trabajador, evitando citar leyes, decretos, reglamentos, entre otros, sin una mayor explicación. En consecuencia, las licencias médicas que sean rechazadas o modificadas por la ISAPRE, deben contener los antecedentes de respaldo en que se fundamentan tales decisiones". ${ }^{46}$ Esta prescripción es valiosa, no solo porque demanda una fundamentación debida, sino también porque exige su claridad: no se puede invocar reglas de Derecho por sí y sin explicarlas; tampoco pueden emplearse términos rebuscados o que no sean de conocimiento y uso común; y siempre deben tenerse presente los antecedentes tenidos a la vista.

\section{EXPLICACIÓN DEL PLAN}

El conjunto de jurisprudencia judicial y administrativa que hemos reunido ha sido ordenado bajo los siguientes "aspectos problemáticos": $1^{\circ}$, el

\footnotetext{
${ }^{43}$ Gordillo, cit. (n. 35), p. X-19.

${ }^{44}$ Gordillo, cit. (n. 35), p. X-20.

45 Véase al respecto el artículo 6, inciso 6.3, de la Ley $N^{\circ} 27.444,2001$, del Perú: “6.3 No son admisibles como motivación, la exposición de fórmulas generales o vacías de fundamentación para el caso concreto o aquellas fórmulas que por su oscuridad, vaguedad, contradicción o insuficiencia no resulten específicamente esclarecedoras para la motivación del acto".

${ }^{46}$ Ministerio de Salud (eds.), Compendio de Normas Administrativas en Materia de Procedimientos, Gobierno de Chile, Superintendencia de Salud, Santiago, 2012, archivo pdf. disponible en línea: http:// www.supersalud.gob.cl/normativa/668/articles-6678_recurso_1.pdf., Capítulo IV, Título II, punto 14.
} 
atingente a la especialidad médica de quien debe emitir la licencia médica y quien debe pronunciarse sobre ella; $2^{\circ}$, la carga de la prueba y su suficiencia para justificar el reposo prescrito; $3^{\circ}$, el reposo fundado en no probarse incapacidad laboral durante el reposo prescrito; $4^{\circ}$, cuándo hay un rechazo mayormente fundado; $5^{\circ}$, el rechazo por diagnóstico irrecuperable; $6^{\circ}$, el rechazo fundado en proyecciones de recuperabilidad; y $7^{\circ}$, el peritaje médico.

Por lo mismo, el orden que seguiremos en nuestro estudio se ciñe a tales aspectos.

\section{EL PROFESIONAL DE LA SALUD COMPETENTE PARA EMITIR UNA LICENCIA Y EL AUTORIZADO PARA PRONUNCIARSE SOBRE ELLA}

Conforme hemos expuesto, solo los médicos-cirujanos, cirujanosdentistas y matronas pueden extender una licencia médica. Pero para ciertas enfermedades -enunciadas en las "Guías Clínicas Referenciales"- se exige que deban ser, en determinados supuestos, otorgadas por un médico-cirujano especialista.

Esta obligación causa un serio problema cuando la licencia extendida llega a manos de quien debe decidir sobre ella: el denominado "médico contralor". Conforme a la actual regulación -al menos para las ISAPRE- ${ }^{47}$ sólo pueden emitir el pronunciamiento los médicos-cirujanos, aun cuando la licencia médica sea dada por otro profesional autorizado para ello. Aunque es evidente la existencia de un claro conflicto de competencias entre distintos profesionales de la salud, la controversia mayor reside cuando quien otorga la licencia médica es un médico-cirujano especialista, y el médico contralor, uno general o de una especialidad diversa.

Para la Corte de Apelaciones de Temuco, el rechazo de una licencia médica realizado por un médico contralor de una ISAPRE que no tenga la misma especialidad médica del profesional otorgante (en este caso, siquiatría), constituye un acto arbitrario (considerando 5). ${ }^{48}$

Es así que podemos estimar que la exigencia de una misma especialidad médica debe ser, a lo menos, base imprescindible para emitir un pronunciamiento negativo. Así, existiría una mayor seguridad de que la resolución se ajustó de forma correcta a los conocimientos especiales de una determinada parcela de las ciencias médicas.

\footnotetext{
${ }^{47}$ Ministerio de Salud, Compendio... cit. (n. 46), Capítulo IV, Título II, punto 1.

${ }^{48}$ Corte de Apelaciones de Temuco, 22 de abril de 1999, R.D.J. T. 96, sec. 5, p. 161.
} 


\section{LA CARGA DE LA PRUEBA Y LA SUFICIENCIA DE LOS ANTECEDENTES}

Por regla general, la licencia médica es producto de un procedimiento médico, en cuya virtud el profesional realiza aquellas gestiones destinadas a comprobar la existencia de una enfermedad que causa una incapacidad para laborar. En consecuencia, y siguiendo a BEsIo, la emisión de licencias médicas es una prerrogativa del profesional de la salud que no puede ser vulnerada por nadie. ${ }^{49}$ Esto incluye el cuestionamiento, la revisión, el rechazo y la reducción del reposo prescrito.

Sin embargo, en nuestro Derecho se prevé, como hemos tratado, la facultad de revisar las licencias extendidas para rechazarlas, ampliarlas o reducirlas por causales de orden médico; la posibilidad de practicar peritajes médicos, y la obligación del profesional tratante de realizar exámenes clínicos y acompañar informes médicos, si la enfermedad está enunciada en las "Guías Clínicas Referenciales". Así, quien extiende la licencia debe probar, con mayor o menor intensidad, la verdad de lo prescrito y de sus fundamentos. Pero, en caso alguno, implica que quien debe emitir el pronunciamiento se desligue de su deber de fundamentar o motivar su decisión, en especial, si es desfavorable para el particular.

La carga probatoria para quien desea la autorización de la licencia médica ha sido también extendida a los supuestos en que el agraviado con el rechazo intenta ejercer algún recurso administrativo o reclamar contra la resolución de su ISAPRE.

Aunque los artículos 59 y 60 de la Ley $N^{\circ} 19.880$, de 2003, no demandan la presentación de antecedentes para interponer un recurso administrativo, la SUSESO, mediante Circular, ${ }^{50}$ exige que siempre deben acompañarse antecedentes para interponerlos, precisándolos según la causal de rechazo; llegando a desechar los recursos deducidos -y de paso confirmando el rechazo de la licencia médica- si no se acompañan. ${ }^{51}$ Este postulado es sostenido también por cierta jurisprudencia de la Corte de Apelaciones de Concepción ${ }^{52}$ y la de Temuco. ${ }^{53}$

\footnotetext{
${ }^{49}$ BEsio, Mauricio, "La licencia médica. Varias dimensiones en un mismo documento. Una propuesta para un mejor uso", Revista Médica de Chile, 2001, Vol. 139, № 11, p. 1504.

${ }^{50}$ Circular $\mathrm{N}^{\circ} 2434,2008$.

${ }^{51}$ Suseso, Dictamen N ${ }^{\circ} 19.393,5$ de julio de 2018.

${ }^{52}$ Corte de Apelaciones de Concepción, 7 de marzo de 2016, rol N 420-2016, de recursos civil.

${ }^{53}$ Corte de Apelaciones de Temuco, 22 de junio de 2018, rol N 2013-2018, protección: "Que de esta forma, si la recurrente no ha acompañado la totalidad de los antecedentes médicos, que justifiquen que
} 
Sin embargo, para el máximo tribunal del país, la carga de probar que el reposo es injustificado corresponde a quien debe emitir el pronunciamiento o resolver el correspondiente recurso administrativo. En sus propias palabras, "la razón expresada por las recurridas deja en evidencia que ambas instituciones han radicado en el recurrente la carga de justificar el reposo que le fuere cursado por su médico tratante" (considerando sexto). ${ }^{54}$

En otra ocasión, y sin hacer mención expresa a la carga de la prueba, la Corte Suprema afirmó que "resulta del todo arbitrario rechazar un permiso médico concedido por facultativos sin ningún antecedente adicional proporcionado por la autoridad recurrida, simplemente sobre la base de la ponderación de los elementos tenidos a la vista, sin un elemento de juicio complementario de contraste, para así esclarecer frente a la paciente y terceros interesados cualquier duda, en particular, sometiéndola a evaluaciones médicas adicionales" (considerando octavo). ${ }^{55}$ Idéntica idea sostuvo la Corte de Apelaciones de Concepción, al decir que es arbitrario e ilegal rechazar una licencia por "información médica insuficiente", sin exponer las razones por las cuales los antecedentes presentados por la recurrente, en particular el informe médico del profesional tratante, no justifican el reposo del recurrente de un modo suficiente (considerando cuarto). ${ }^{56}$

el prolongado reposo, se encuentre justificado médicamente, y resulte indispensable para la recuperación de su salud y vuelta al trabajo, de acuerdo a la patología de que dan cuenta, no cabe sino estimar que la recurrente carece del derecho indubitado para la aprobación y pago de las referidas licencias, de forma que la resolución que motiva el recurso, tampoco resulta arbitraria" (considerando cuarto).

${ }^{54}$ Corte Suprema, 26 de noviembre de 2018, rol No 19005-2018. La misma sentencia agrega, en su considerando quinto, lo siguiente: "Que, como correctamente lo expresa la disidencia en el fallo apelado, la contradicción que surge entre la autorización de las licencias médicas cursadas antes del 5 de noviembre de 2017 y el rechazo de tales instrumentos a partir de aquel momento, requiere que la decisión denegatoria fundamente, motive o justifique suficientemente la razón de tal discordancia, exigencia que, en la especie, no ha sido satisfecha".

55 Corte Suprema, 11 de enero de 2018, rol N 40188-2017. Así también Corte Suprema, 30 de marzo de 2017, rol № 87815-2016; y Corte Suprema, 19 de junio de 2018, rol ํ 5321-2018. En un sentido similar, Corte de Apelaciones de Temuco, 22 de mayo de 2018, rol N 1437-2018, protección (confirmada por sentencia de Corte Suprema, 27 de junio de 2018, rol N 12624-2018); Corte de Apelaciones de Concepción, 6 de octubre de 2016, rol N 19013-2016, de recursos civil.

${ }^{56}$ Corte de Apelaciones de Concepción, 28 de junio de 2017, rol № 3298-2017, de recursos civil. En un sentido semejante, Corte de Apelaciones de Concepción, 17 de agosto de 2018, rol N 5104-2018 protección; y Corte de Apelaciones de Concepción, 6 de abril de 2017, rol № 328-2017, de recursos civil: "aparece de la escasa información que tomó en cuenta la recurrida para motivar su rechazo, que ésta resulta ser insuficiente para fundamentar una resolución en tal sentido, toda vez que el informe médico recién mencionado no fue contradicho con algún informe complementario o un peritaje médico, si a juicio de la recurrida existían dudas o reparos al diagnóstico del médico especialista (...) que atendía a la paciente cuya licencia le fue objetada. En consecuencia, se echan de menos, entonces, otros antecedentes que hubieren corroborado o ratificado aquella suposición de la compIN reclamada, 
De esta manera, lo afirmado por BESIO resulta confirmado.

Este grupo de resoluciones -extrapolables a cualquier instancia resolutiva, sea pública o privada-nos permite sostener que, por regla general, la incuestionabilidad de la licencia médica debe ser admitida; más aún si el profesional se sometió a lo prescrito por las Guías Clínicas Referenciales, cuando correspondiere. Además, este razonamiento es coherente con la afirmación de BERMÚDEZ (aplicable a los actos administrativos) en orden a la carga de la prueba. Y es concordante, además, con la regla general de argumentación de Alexy.

Pero, en otras oportunidades, la Corte de Apelaciones penquista declaró legal el rechazo, debido que, en su parecer, el rechazo de una licencia médica por "reposo injustificado", y fundado en que no está justificado con antecedentes disponibles, se ajusta a Derecho, pues el pronunciamiento consta en el respectivo formulario y, además, "en este se deja constancia de los fundamentos tenidos en vista para adoptar tal medida" (considerando 11). ${ }^{57}$ Sin lugar a dudas, de ella se puede desprender que el estándar para rechazar la licencia médica sería exiguo. ¿Cuáles son los antecedentes? Nadie sabe. ¿Por qué no está justificado el reposo? Nadie lo sabe. ¿Cuál es el fundamento del rechazo? Que no está justificado el reposo. ¿Y por qué no lo está? Porque los antecedentes que nadie sabe cuáles son así lo permiten suponer.

En una sentencia diversa, el mismo tribunal declaró fundado un rechazo de licencia por "periodo de reposo solicitado no justificado con antecedentes médicos aportados en el informe médico complementario y peritaje, artículo 21 del DL 3-84", pues el acto no solo se funda en normas reglamentarias, "sino que además, su argumento se ajusta a los motivos que permiten esa decisión; pues, en efecto, la resolución se refiere a la necesidad de contar con otros antecedentes médicos y que alteren lo concluido en dicho peritaje y, en consecuencia, el motivo que autoriza la confirmación del rechazo de dicha licencia médica, existió" (considerando $\left.7^{\circ}\right) .{ }^{58}$

\footnotetext{
y precisamente esos otros antecedentes podían haber sido sumados en este caso por la recurrida" (considerando $6^{\circ}$ ).

${ }^{57}$ Corte de Apelaciones de Concepción, 21 de septiembre de 2012, rol No 1745-2012, civil. Así también, Corte de Apelaciones de Concepción, 24 de septiembre de 2012, rol No 1667-2012, civil.

${ }^{58}$ Corte de Apelaciones de Concepción, 23 de marzo de 2017, rol No 419-2017, de recursos civil.
} 


\section{EL RECHAZO POR NO ACREDITARSE INCAPACIDAD LABORAL DURANTE EL PERÍODO DE REPOSO PRESCRITO}

Muchos dictámenes de la sUSESO rechazan las apelaciones y reconsideraciones deducidas por los agraviados y, por consecuencia, los reposos prescritos en las licencias médicas, exponiendo tan solo que éstos no se encuentran médicamente justificados, por cuanto no se acreditó incapacidad laboral durante dicho periodo. ${ }^{59}$ Otros mencionan que la licencia no se justificaba médicamente ${ }^{60}$ o que, del estudio de los antecedentes que obran en el expediente, el reposo no se justifica; ${ }^{61}$ o que se rechaza por considerarse suficiente el otorgado previamente para la normal evolución de las patologías; ${ }^{62}$ o que, luego de estudiar los antecedentes tenidos a la vista, no se encuentran justificadas las licencias médicas. ${ }^{63}$

Estos dictámenes merecen una serie de observaciones. Primero, el exigir al trabajador probar que el reposo es justificado no solo contraviene lo que el máximo tribunal del país ha sustentado en este último tiempo, sino también a lo afirmado por BERMúDEZ y por AleXY.

Segundo, aunque aludan a antecedentes que se tuvieron a la vista, no son ni enunciados ni detallados, lo cual no da a la resolución la suficiente claridad para su entendimiento.

Y tercero, no entregan motivos para entender por qué los antecedentes tenidos a la vista o reestudiados no permiten justificar el reposo, cuando es obligatorio. Lo mínimo que se podría esperar, vista la gravedad de los efectos que acarrea el rechazo de una licencia médica, es un estudio más o menos acabado de esos antecedentes.

Todo indica, por consiguiente, que los dictámenes se sustentan en frases cliché. Y con justa razón, han terminado convirtiéndose en objetos de

\footnotetext{
${ }^{59}$ SusESo, Dictamen 8893, 9 de febrero de 2007; SusEso, Dictamen 36882, 8 de junio de 2007; Suseso, Dictamen 1251, 8 de enero de 2010; SuSESO, Dictamen 1851, 12 de enero de 2010; SuSESO, Dictamen 9117, 15 de febrero de 2010; SusEso, Dictamen 9611, 18 de febrero de 2010; SuSESo, Dictamen 10815, 24 de febrero de 2010; Suseso, Dictamen 10820, 24 de febrero de 2010; Suseso, Dictamen 20023, 7 de abril de 2010; Suseso, Dictamen 27585, 6 de mayo de 2010; Suseso, Dictamen 56081, 14 de septiembre de 2011; y Suseso, Dictamen 17132, 19 de junio de 2018.

${ }^{60}$ Suseso, Dictamen 62952, 7 de octubre de 2008.

${ }^{61}$ SusEso, Dictamen 17484, 26 de marzo de 2010.

${ }^{62}$ Suseso, Dictamen 7528, 7 de marzo de 2001; Suseso, Dictamen 51781, 19 de octubre de 2009; Suseso, Dictamen 68078, 28 de diciembre de 2009; Suseso, Dictamen 1865, 12 de enero de 2010; y Suseso, Dictamen 12957, 10 de marzo de 2010.

${ }^{63}$ Suseso, Dictamen 255, 3 de enero de 2012.
} 
recursos de protección, con disímiles resultados.

Por un lado, y para la Corte de Apelaciones de Concepción, que la resolución de la SUSESO indique que el informe médico aportado no permite establecer incapacidad laboral temporal más allá del periodo de reposo ya autorizado es un fundamento suficiente para rechazar la licencia médica, pues señala que efectuó un estudio del informe médico que le permitió concluir de la forma que lo hizo (considerando séptimo). ${ }^{64} \mathrm{Si}$ ya este razonamiento resulta dudoso, habida cuenta de que el dictamen no menciona qué informe tuvo a la vista ni da mayores razones para el rechazo -no menciona siquiera el procedimiento lógico que permitió arribar a tamaña conclusión- lo que de verdad resulta irritante es que afirma que el reproche de la recurrente no es más que un desacuerdo con la conclusión médica que arriba la SUSESO (considerando octavo). ${ }^{65}$

A juicio de la Corte de Apelaciones de Puerto Montt, el rechazo de la SUSESO a la apelación fundado a que no se puede establecer incapacidad laboral más allá del período autorizado, no es arbitrario e ilegal, pues la recurrida se basó en exámenes médicos practicado por ella misma, mediante profesionales dotados de aptitud técnica para ello, cuyos resultados impedían justificar el reposo prescrito por el profesional tratante (considerando séptimo); ${ }^{66}$ exámenes y profesionales que, dicho sea de paso, no son enunciados en el acto recurrido.

Según la Corte de Apelaciones de Temuco, la resolución de la SUSESO que rechaza una apelación por rechazo de licencias médicas está fundado, pues su contenido -que transcribe-señala que el informe médico aportado no permite establecer incapacidad laboral temporal más allá del período de reposo ya autorizado (considerando noveno). ${ }^{67}$ De nuevo habría que preguntarse qué informe médico fue aportado y por qué resulta insuficiente para justificar la ausencia laboral.

En un sentido semejante, el tribunal de alzada de la capital del Bío Bío declaró ajustado a Derecho la resolución de la SUSESO en orden a desechar

\footnotetext{
${ }^{64}$ Corte de Apelaciones de Concepción, 7 de marzo de 2018, rol № 8506-2017, de recursos civil (revocada por sentencia de Corte Suprema, 19 de junio de 2018, rol No 5321-2018). En un sentido semejante, Corte de Apelaciones de Concepción, 30 de julio de 2012, rol No 1349-2012, civil. Hay que considerar, no obstante, que el recurso intentado fue rechazado por extemporáneo.

${ }^{65}$ Corte de Apelaciones de Concepción, 7 de marzo de 2018, rol N ${ }^{\circ}$ 8506-2017, de recursos civil (revocada por sentencia de Corte Suprema, 19 de junio de 2018, rol ํ5 5321-2018).

${ }^{66}$ Corte de Apelaciones de Puerto Montt, 18 de noviembre de 2016, rol No 2394-2016, protección.

${ }^{67}$ Corte de Apelaciones de Temuco, 16 de agosto de 2018, rol N²766-2018, protección.
} 
una reconsideración por no acompañar nuevos antecedentes, pues "ante la ausencia de los referidos antecedentes médicos, la resolución recurrida fundada en la falta de aquellos — a lo menos - aparece sustentada en una motivación explicativa para la decisión de rechazo en ella contenida, lo que excluye entonces la arbitrariedad e ilegalidad que le atribuye el recurrente" (considerando $7^{\circ}$ ). ${ }^{68} \mathrm{~A}$ diferencia de las otras sentencias, sí se puede acordar con lo sustentado por la Corte, pues, en estricto rigor, el acto impugnado es una reconsideración o, como sostiene la Contraloría General de la República, un recurso extraordinario de revisión. ${ }^{69}$ La postura contraria podemos encontrarla en la Corte de Apelaciones de Puerto Montt, cuando declaró que es arbitrario e ilegal rechazar una reconsideración sin hacerse cargo del fondo de las causales de rechazo de las licencias, desarrollando un análisis de los antecedentes de salud de la actora y evaluar nuevamente, si fuere necesario, su estado de salud (considerando séptimo). ${ }^{70}$

En otro fallo del tribunal de alzada de Temuco, la resolución de la SUSESO que declaró que el informe médico aportado no permite establecer incapacidad laboral temporal más allá del período de reposo ya autorizado, se apoya en los antecedentes aportados por el recurrente al momento de apelar del rechazo de las licencias por la correspondiente COMPIN. En particular, la sentencia alude a dos informes médicos otorgados por el profesional tratante, que relatan la evolución positiva de su paciente (considerando quinto) ${ }^{71}$ informes que no son individualizados en el acto administrativo del órgano fiscalizador. Así, en su parecer, la SUSESO no actuó de forma arbitraria ni ilegal, rechazando el recurso intentado. En una situación similar, la Corte de Apelaciones de Santiago, conociendo sobre un recurso de protección

\footnotetext{
${ }^{68}$ Corte de Apelaciones de Concepción, 27 de julio de 2018, rol № 6795-2018, protección.

${ }^{69}$ Contraloría General de la República, Dictamen Nº 94157, 4 de diciembre de 2014.

${ }^{70}$ Corte de Apelaciones de Puerto Montt, 24 de marzo de 2017, rol Nº 154-2017, protección, revocada por sentencia de Corte Suprema, 18 de mayo de 2017, rol № 10406-2017. El máximo tribunal del país estimó que no hay acto arbitrario e ilegal, debido a que el rechazo de las licencias médicas confirmado por la SUSESO se funda en el contenido del informe protocolizado del médico tratante, informe que no es identificado a plenitud en el acto recurrido y cuyo contenido tampoco es desarrollado.

La Corte de Apelaciones de Temuco, declaró arbitrario e ilegal el rechazo a una reconsideración que rechazó las licencias médicas, pues "no justificó ni desvirtuó debidamente, debiendo haberlo hecho, la incapacidad laboral temporal diagnosticada por el médico tratante, de manera que los fundamentos plasmados en la ya citada resolución, que resuelve la reclamación de la resolución de la licencia médica, resulta insuficiente para resolver el rechazo y no otorgar el pago de la misma" (considerando séptimo), Corte de Apelaciones de Temuco, 7 de septiembre de 2017, rol № 2668-2017, protección (revocada por sentencia Corte Suprema, 19 de febrero de 2018, rol N³9714-2017).

${ }^{71}$ Corte de Apelaciones de Temuco, 4 de agosto de 2017, rol No 2982-2017, protección.
} 
deducido contra un dictamen de la SUSESO, expuso que ésta confirmó el rechazo emitido por la COMPIN mediante una resolución debidamente fundada, sin que, aquí, se le pueda exigir un estándar motivacional elevado (considerando octavo). ${ }^{72-73}$

Pero la sentencia que avaló un estándar de fundamentación exiguo la emitió la Corte de Apelaciones de Concepción, basándose en el artículo 16 del Reglamento. Así, entendió que tal disposición "no reglamenta la forma del razonamiento ni la extensión de los fundamentos que deben esgrimirse para rechazar una licencia médica, o la reposición en contra del rechazo de la misma, por lo que es suficiente remitirse a los antecedentes y a un peritaje efectuado al paciente" (considerando $\left.16^{\circ}\right) \cdot{ }^{74}$ Es claro que el tribunal desconoce lo que la Ley $\mathrm{N}^{\circ} 19.880$, de 2003, exige para los actos administrativos de contenido desfavorable y para los que resuelven recursos administrativos, lo cual resulta sorprendente.

La opinión opuesta es sustentada por la Corte Suprema, cuando afirmó que "la decisión adoptada por la Superintendencia no está apoyada por ningún elemento de convicción que la avale más que la referencia a 'los antecedentes y su mérito' como tampoco hace mención a otros factores objetivos que permitan corroborar la decisión a que arriba, en cuanto a la suficiencia del reposo médico ya otorgado sin que tampoco explicite los motivos por los que el plan terapéutico resultaría incompatible con la extensión del reposo, carencias que la privan de contenido, no pudiéndose concluir que aquélla se basta a sí misma si no ofrece los elementos de juicio necesarios que permitan comprenderla y entender por qué la recurrente no necesitaba más días de descanso que los ya otorgados" (considerando sexto). ${ }^{75}$ Lo mismo sostuvo la Corte de Apelaciones de La Serena respecto

\footnotetext{
${ }^{72}$ Corte de Apelaciones de Santiago, 11 de enero de 2017, rol No 118499-2016, protección.

${ }^{73} \mathrm{La}$ Corte de Apelaciones de Santiago estimó fundado los actos de la COMPIN al indicar que "aparecen fundamentados y por ende, no cabe motejarlos de ilegales o arbitrarios, sinónimo de caprichosos, desde que dan razón del porqué se resuelve en la forma que en ellos se expresa y en este aspecto, refieren a criterios médicos a los que se ajustó la citada Comisión al tiempo de resolver sobre la procedencia del subsidio independiente de otras consideraciones razón por la que se desestimará el presente recurso deducido en su contra" (considerando cuarto). Corte de Apelaciones de Santiago, 18 de octubre de 2016, rol No 100008-2016, protección.

${ }^{74}$ Corte de Apelaciones de Concepción, 30 de abril de 2014, rol No 1709-2014, de recursos civil.

${ }^{75}$ Corte Suprema, 19 de junio de 2018, rol N 5321-2018. Este fallo revoca el dictado por la Corte de Apelaciones de Concepción, señalado inmediatamente arriba. Así también Corte Suprema, 11 de enero de 2018, rol No 40188-2017; Corte Suprema, 10 de mayo de 2018, rol N 841-2018; Corte Suprema, 19 de febrero de 2018, rol No 41367-2017; Corte Suprema, 5 de marzo de 2018, rol No 31-2018; Corte Suprema, 14 de noviembre de 2017, rol N $35289-2017$.
} 
del rechazo por "reposo prolongado" a secas, sin dar mayores razones o, derechamente, omitiéndolas (considerando octavo). ${ }^{76}$

Lo relevante de estas sentencias está en la circunstancia de que, con prescindencia de quién emite la resolución o si se trata o no de un recurso administrativo, siempre se debe exponer, con la debida extensión y claridad, las razones que motivan el rechazo de una licencia médica. No importa si es la COMPIN conociendo de una reposición o la SUSESO de una apelación, siempre deben dar razones-claras, precisas y completas-de su actuar. En consecuencia, la alusión de frases cliché o de estilo queda por completo vedada.

\section{RECHAZOS MAYORMENTE FUNDADOS}

En muchísimas ocasiones, la SUSESo ha dado varias razones para rechazar una licencia o revocar una autorización anterior. Así, y aunque la causal de rechazo fue de orden jurídico-administrativa, siguiendo la conclusión de su Departamento Médico, entendió que la licencia debía ser también rechazada, pues no se sabía qué procedimiento quirúrgico abdominal se empleó en el paciente: si la operación fue por laparoscopía, la recuperación y el reposo prescrito son breves, por lo que el reposo es prolongado, y por mucho; y si se usó el procedimiento tradicional, el reposo prescrito también es excesivo. Además, y como refuerzo, esgrimió no haber constancia alguna de complicaciones a consecuencia de la intervención. ${ }^{77}$ Según podemos advertir, la declaración de reposo prolongado se funda en una falta mayúscula de antecedentes tenidos a la vista. Pero lo más grosero no es esta ausencia de antecedentes, sino el hecho de que la SUSESO no se procuró acceder a ellos, pudiendo hacerlo.

En otra ocasión, concluyó en el mismo sentido cuando, habiendo solicitado un informe a su Departamento Médico, éste informó que las licencias tienen como diagnóstico una hernia del núcleo pulposo L4-L5, ${ }^{78}$ y que "la resonancia magnética lumbar señala expresamente que: ' $\mathrm{HNP}^{79}$ posteromedial de base ancha L4 L5, no determina conflicto de espacio'. Esto significa que se trata de una protrusión discal que no comprime ninguna raíz y por ende no constituye causal de dolor de ningún tipo. Lo

\footnotetext{
${ }^{76}$ Corte de Apelaciones de La Serena, 6 de octubre de 2016, rol No 1547-2016, civil.

77 SusEso, Dictamen 30875, 17 de mayo de 2013.

${ }^{78}$ L4-L5 hacen referencia a las vértebras lumbares 4 y 5.

${ }^{79}$ Entiéndase "hernia del núcleo pulposo".
} 
que sí muestra la resonancia es una patología de tipo degenerativo crónico, probablemente muy antigua", agregando que, "por ende, el reposo indicado bajo ese diagnóstico, no se encuentra médicamente justificado, ya que no se trata de una incapacidad no temporal. ${ }^{80}$

En otro dictamen dispuso que el reposo prescrito no se justificaba, ya que el examen imagenológico realizado y de ecografía no muestra alteraciones mayores, como roturas tendíneas, que justifiquen el reposo. ${ }^{81}$ Si bien especifica la existencia de exámenes médicos y sus resultados, no son detallados con suficiencia.

También rechazó la licencia médica, basado en el largo período de reposo previo; en que el diagnóstico principal de las licencias médicas apeladas — hipertensión arterial—, no guarda relación con lo prolongado del reposo; y en que la situación conflictiva laboral y judicial que se le ha presentado al operario no tiene un componente médico incapacitante. ${ }^{82}$ Aquí, podemos darnos cuenta que la SUSESO descarta que, tanto una enfermedad determinada como el historial de conflictos del paciente, tengan incidencia en la extensión del reposo prescrito.

En otro dictamen, expuso que, de los antecedentes analizados (que no enuncia), no hay elementos técnicos concordantes que acrediten incapacidad laboral de la paciente, ni que sostengan la gravedad del cuadro, expresada por el médico tratante en el diagnóstico de las licencias médicas. ${ }^{83}$

La SUSESo igual declaró injustificado el reposo, fundado en que el trabajador presentó licencias médicas discontinuadas y por una misma patología, lo que, a su juicio, resulta incongruente ${ }^{84}$ Aunque a primera vista pareciere que el razonamiento es escueto, es evidente que, aquí, primó la lex artis médica y el sentido común, razones que resultan ser suficientes hasta para una persona de conocimientos medianos.

\section{RECHAZOS POR SALUD IRRECUPERABLE}

Según vimos arriba, la salud irrecuperable podría configurarse como causal de rechazo de una licencia médica. La SUSESo, en este orden, ha

\footnotetext{
${ }^{80}$ SuSESO, Dictamen 70675, 8 de noviembre de 2013.

${ }^{81}$ Suseso, Dictamen 38215, 15 de junio de 2012.

82 Suseso, Dictamen 62111, 24 de noviembre de 2006.

${ }^{83}$ Suseso, Dictamen 21874, 31 de marzo de 2008.

${ }^{84}$ SusEso, Dictamen 11662, 4 de marzo de 2010.
} 
concluido que una licencia médica es injustificada cuando versa sobre una patología irrecuperable, pues las alteraciones que el trabajador presenta son de curso crónico y no susceptibles de modificar con reposo; añadiendo que los informes médicos concuerdan en que la enfermedad le produce actualmente algún grado de incapacidad, la que por el tiempo transcurrido y su persistencia a pesar del tratamiento, se considera definitiva ${ }^{85}$ Los términos transcritos se repiten en un buen número de dictámenes como frases de estilo, sin hacer mayores añadiduras ni distingos de ninguna clase. De modo tal que, y siguiendo a Gordillo, no habría una real fundamentación, pues serían expresiones repetitivas sin contenido alguno.

Además, tampoco se hacen cargo de lo que la misma suseso ha sostenido respecto de la salud irrecuperable, y que expusimos arriba, incurriendo así en una eventual contradicción.

En otras oportunidades, agrega de forma expresa como razón la cantidad de días de reposo, declarándolo, en consecuencia, prolongado e injustificado; exponiendo además que el trabajador no ha iniciado la tramitación de una pensión de invalidez según su régimen previsional, sin que existan antecedentes de hospitalizaciones o cuadros de crisis, que avalen una gravedad e intensidad de esta, ni la extensión de un reposo tan extenso. ${ }^{86}$

También ha mencionado la circunstancia de que el período de reposo antes autorizado era suficiente para obtener la curación del cuadro clínico y su reintegro al trabajo, lo que no ocurrió; entendiendo que la dolencia produce una incapacidad para trabajar que no es susceptible de revertir, por lo que probablemente el trabajador presenta una incapacidad no temporal, por lo que no procede autorizar licencias médicas.$^{87}$ Lo controvertido de esta decisión reside en la existencia de dos especulaciones: que el trabajador se recuperaría dentro de cierta fecha, lo que no acaeció; y que probablemente presenta una incapacidad no temporal. La primera obedece a diferencias de criterios médicos, y la segunda, a la falta de verificación de un hecho que pudo o no ocurrir. La SUSESO emplea el término probablemente, asumiendo

\footnotetext{
${ }^{85}$ SusEso, Dictamen 624, 7 de enero de 2005; Suseso, Dictamen 9503, 9 de febrero de 2012; SuSESO, Dictamen 51003, 6 de agosto de 2014; Suseso, Dictamen 68237, 15 de agosto de 2014; y SusESo, Dictamen 69055, 30 de noviembre de 2015. En un sentido semejante: SusESo, Dictamen 254, 3 de enero de 2012.

${ }^{86}$ SuSESO, Dictamen 6132, 2 de febrero de 2016.

${ }^{87}$ Suseso, Dictamen 76296, 13 de diciembre de 2013. En un sentido semejante, SusESo, Dictamen 1731-2001, 17 de enero de 2001; Suseso, Dictamen 4918, 1 de febrero de 2002; y SusEso, Dictamen 4872, 1 de febrero de 2003.
} 
de antemano una posibilidad sin que existan pruebas concluyentes que permitan acreditar su teoría o aceptar una contraria. La irrecuperabilidad, atendida la gravedad de sus efectos, debe ser determinada con contundencia; condición que, aquí, no está comprobada.

En varias ocasiones, al razonamiento ya enunciado, se añade la existencia de resoluciones de la Superintendencia de Pensiones pronunciándose sobre declaraciones de invalidez -afirmativas o negativascomo elemento motivador; ${ }^{88}$ dándoles una gran relevancia.

Y a nivel de jurisprudencia judicial, la Corte de Apelaciones de Concepción estimó que los antecedentes acompañados al proceso $\mathrm{y}$, en particular, el expediente administrativo agregado, permiten determinar que las patologías que padece el recurrente "han tenido un curso cronificado, mostrando en su evolución una incapacidad no temporal y por ende, no susceptible de modificar con el reposo continuo que ha tenido, lo que ve corroborado por la circunstancia de contar con reposo por más de 1374 días autorizados, situación que resulta incompatible con el derecho a la licencia médica, que es de naturaleza esencialmente temporal y cuya finalidad última es ayudar al trabajador afectado por una incapacidad temporal a recuperar su salud y reincorporarse a su actividad laboral" (considerando $\left.5^{\circ}\right){ }^{89}$ Lo interesante del fallo radica en la trascendencia del expediente administrativo por sobre el texto mismo del pronunciamiento recaído sobre la licencia, condición que debe ser, por lo menos, puesta en sospecha. Según podemos observar, para el tribunal es bastante fundar el rechazo invocando la expresión genérica que la suSESo emplea y enunciando los días de reposo ya autorizados, estimando que, por su alto número, ya no hay temporalidad de la enfermedad. En un sentido similar falló la Corte Suprema, pero sin hacer referencia a los antecedentes allegados a la causa. ${ }^{90}$

La Corte de Apelaciones de Santiago consideró infundado, por insuficiente, el rechazo de las licencias médicas basado en que "estas implicaban un reposo prolongado de la recurrente, perdiéndose el fin legal de una licencia médica, cual es, precisamente, proteger una incapacidad

\footnotetext{
${ }^{88}$ Suseso, Dictamen 35751, 6 de junio de 2012. En un sentido semejante, Suseso, Dictamen 47623, 15 de julio de 2008; y SuSESo, Dictamen 53789, 24 de agosto de 2010.

${ }^{89}$ Corte de Apelaciones de Concepción, 27 de agosto de 2018, rol N ${ }^{\circ}$ 5932-2018, protección. En un sentido semejante, Corte de Apelaciones de Concepción, 28 de agosto de 2018, rol № 6765-2018, protección (confirmada por Corte Suprema, 30 de octubre de 2018, rol ํ 22185-2018), y Corte Suprema, 11 de abril de 2017, rol $\mathrm{N}^{\circ}$ 309-2017.

${ }^{90}$ Corte Suprema, 24 de noviembre de 2016, rol No $58877-2016$.
} 
transitoria", habida consideración a que el estado de salud del recurrente justificó su inasistencia a su trabajo por el tiempo prescrito por su médico tratante, y a lo informado y documentos acompañados al proceso por el recurrido (considerando sexto). ${ }^{91}$ Como puede verse, el tribunal le da valor al hecho de que el trabajador esté incapacitado para laborar, aunque fuera por un tiempo prolongado. Pasa así la posibilidad de sustentar un rechazo por salud irrecuperable en virtud de plazos a ser dubitativa, pues no implicarían per se la existencia de una invalidez.

La Corte Suprema declaró ilegal, por infundado, el rechazo de una licencia basado en una declaración de invalidez rechazada por el organismo competente (considerando séptimo). ${ }^{92}$ Resulta así que es posible acogerse a resoluciones de otros órganos para motivar un pronunciamiento recaído en una licencia médica es factible, a condición de que sea coherente con la decisión de rechazo.

En el parecer de la Corte de Apelaciones porteña, es infundado rechazar una licencia médica por salud irrecuperable por parte de una ISAPRE, si el acto recurrido se limita a enunciar la causal de forma genérica añadiendo una referencia al artículo $1^{\circ}$ del Reglamento; sin perjuicio de que, en estricto rigor, la declaración de salud irrecuperable es de competencia de la cOMPIN o de la Comisión Médica Regional respectiva (considerando octavo). ${ }^{93} \mathrm{El}$ tribunal advierte, además, que a la recurrente (enferma de cáncer) no se le hizo pericia alguna por parte de la ISAPRE en orden a determinar su estado y evolución; recuerda que está en pleno tratamiento médico; y tiene presente, en particular, lo que la SUSESO entiende sobre la salud irrecuperable y que transcribimos arriba (considerandos sexto, octavo, noveno y undécimo). ${ }^{94}$

Por último, la Corte de Apelaciones penquista estimó infundado el rechazo de una licencia médica, por parte de una ISAPRE, basado tan solo en que el trabajador es "pensionado", y por ser, además, la patología irrecuperable, sin ejercer las potestades que el Reglamento le confiere para mejor resolver (considerandos tercero y sexto). ${ }^{95}$ Añade que la conclusión de irrecuperabilidad es una cuestión que, en su concepto, requiere antecedentes

\footnotetext{
${ }^{91}$ Corte de Apelaciones de Santiago, 3 de noviembre de 2009, rol № 767-2009, protección.

${ }^{92}$ Corte Suprema, 24 de diciembre de 2018, rol N N $^{\circ} 23244-2018$.

${ }_{93}$ Véase al respecto el artículo 22 del Decreto $\mathrm{N}^{\circ} 3,1984$.

${ }^{94}$ Corte de Apelaciones de Valparaíso, 3 de junio de 2010, rol № 185-2010, protección.

${ }^{95}$ Corte de Apelaciones de Concepción, 22 de marzo de 2012, rol № 185-2012. En un sentido semejante, Corte de Apelaciones de Temuco, 11 de diciembre de 2012, rol 2016-2012, protección.
} 
serios y fehacientes, distintos a una mera certificación singular que, por lo demás, no es directa en cuanto a ese punto, sino que constituye una simple inferencia efectuada por sí y ante sí por la propia recurrida (considerando sexto). ${ }^{96}$

Según podemos apreciar, de este conjunto de jurisprudencia se destaca algo muy importante: la causal de salud irrecuperable es más complicada de lo que se puede pensar. Se requieren mayores antecedentes y razones más que contundentes y suficientes. Si bien el recurso de los días de reposo autorizado puede ser un buen fundamento, debe ser aplicado con mucha cautela, debido a lo que dijimos en su momento. De igual manera, si se quiere sustentar el rechazo en una resolución de invalidez, hay que considerar, por sobre todo, a cuánto asciende el porcentaje de invalidez: no se puede fundar un rechazo si la invalidez equivale a $0 \%$ o al $5 \%$.

Además, no podemos dejar de lado que un elemento de importancia es lo que la propia SUSESO ha expuesto sobre la salud irrecuperable: una enfermedad crónica o irrecuperable no constituye, por sí sola, una causal de rechazo.

\section{EL ALEGATO A PROYECCIONES DE RECUPERABILIDAD}

Algunos rechazos, en particular si se tratan de salud irrecuperable, se fundan en proyecciones de recuperabilidad del paciente. En palabras breves, se sustentan en meras expectativas.

Aunque debemos reconocer que, como ciencia, la Medicina puede establecer la evolución de una enfermedad con mayor o menor exactitud, también tenemos que afirmar que las proyecciones que haga pueden ser erradas o alteradas por otros sucesos, sean o no controlables. Por ejemplo, a una persona que sufre una fractura, se le puede informar un plazo dentro del cual el hueso quede soldado. Pero entre el día del accidente y la fecha presunta de recuperación, puede acaecer cualquier suceso que termine echando por la borda la proyección: una infección, otro accidente o el incumplimiento de las indicaciones médicas, por parte del paciente, pueden importar que la proyección no se cumpla.

Por lo mismo, recurrir a ellas ha sido rechazada por la Corte de Apelaciones penquista, quien estableció "que la decisión de la recurrida resulta arbitraria pues no se funda en antecedentes médicos actuales y

${ }^{96}$ Corte de Apelaciones de Concepción, 22 de marzo de 2012, rol 185-2012, civil. 
suficientes, sino sólo en proyecciones de la recuperabilidad de la paciente, situación que no ha resultado efectivamente comprobada por un profesional médico competente. En efecto, en el hecho existe la opinión del profesional médico tratante del paciente, quien extiende la licencia médica por 30 días de reposo a contar del 9 de abril del año en curso y, por otro lado, está la opinión del médico de compin, quien estima que el reposo debe concluir el día 8 de dicho abril, sin que exista una nueva opinión médica que se contraponga a la del médico tratante" (considerando 6). ${ }^{97}$

Aquí debemos resaltar algo sustancial: el tribunal no le está negando validez a la opinión del facultativo de la compin porque él la emita, sino que la entiende desfasada en el tiempo, esto es, no vigente a la fecha en que el profesional tratante emitió la licencia médica rechazada. Si bien médicamente puede establecerse un pronóstico, atendido los conocimientos científicos y los exámenes que se practiquen, adolecerá del vicio de ser especulativo. Es deber de cualquier actividad científica probar y comprobar sus postulados y afirmaciones; lo que, en este supuesto, no se realizó.

\section{EL PERITAJE MÉDICO}

\section{Presentación}

Atendida la circunstancia de que, como hemos expuesto, la carga de la prueba reside en quien debe emitir el pronunciamiento o resolver el recurso, surge el problema relacionado con la práctica de peritajes médicos. Conforme a lo tratado arriba, éste es una medida para mejor resolver que puede decretar la COMPIN, la Unidad de Licencias Médicas o las ISAPRE -y también la SUSESO- en cuya virtud un profesional de la salud competente y experto realiza un estudio médico del paciente, tendiente a determinar, entre otras consideraciones, si existe la enfermedad o si el reposo prescrito se encuentra justificado del punto de vista clínico.

Aunque es evidente la conveniencia de esta práctica para fundar un pronunciamiento, ella presenta una serie de problemas, que podemos reducir a los siguientes: $1^{\circ}$ cuándo procede practicarlo; $2^{\circ}$ cuál es su valor per se; $3^{\circ}$ cuál es su valor temporal; $4^{\circ}$ la imparcialidad de quien practica el peritaje; $5^{\circ}$ si la mención a la existencia del peritaje es bastante para justificar un rechazo.

97 Corte de Apelaciones de Concepción, 8 de julio de 2014, rol 2349-2014, de recursos civil. 


\section{Cuándo procede practicar un peritaje}

En lo que dice relación con este punto, la Corte Suprema, sin tratarlo de modo directo, ha sido tajante al afirmar que "no corresponde colocar al trabajador la carga de justificar el reposo prescrito, sin ordenar la práctica de examen alguno útil para establecer el estado actual de las dolencias que aquejan a (...) y sus consecuencias respecto a su aptitud laboral, limitándose a realizar una revisión formal de los antecedentes que obraban en su poder" (considerando sexto). ${ }^{98}$ Idea semejante se desprende de los otros fallos del mismo tribunal, vistos al estudiar la carga de la prueba.

Como bien podemos advertir, es destacable la obligación de quien debe emitir el pronunciamiento (o fallar el recurso administrativo) de practicar $\mathrm{u}$ ordenar la práctica del peritaje, cuando existiere alguna duda o reparo al reposo prescrito. Este razonamiento concuerda con la carga de motivación de la Administración y lo sostenido por BesIO y por AleXY.

\section{Valor per se del peritaje}

En lo tocante al valor por sí solo del peritaje, el máximo tribunal del país le dio en una oportunidad tanto valor a uno que llegó a afirmar que el informe médico emitido por el profesional tratante "no contienen elementos convincentes que contradigan la opinión del experto" (considerando cuarto). ${ }^{99}$ En otras palabras, los resultados del peritaje constituyeron plena prueba.

¿Pero es posible darle tamaño valor? Todo indica que no. El peritaje debe ser apreciado en su justa medida. En otros términos, debe tenerse en consideración los conocimientos y la experticia de quien lo emite; si se ajusta a criterios técnicos aceptados por la comunidad científica, y si se encuentra debidamente fundado.

En todo caso, debemos considerar que, cualquiera sea quien deba emitir el pronunciamiento, siempre está la posibilidad de que el peritaje sea impugnado por la parte interesada. Ello no es más que consecuencia de la aplicación del principio de la bilateralidad de la audiencia, extrapolado a este asunto.

\footnotetext{
${ }^{98}$ Corte Suprema, 26 de noviembre de 2018, rol ํㅜ 19005-2018. Así también Corte Suprema, 24 de diciembre de 2018, rol No N $^{\circ} 23244-2018$. En un sentido semejante, Corte Suprema, 8 de noviembre de 2018, rol No $15124-2018$.

${ }^{99}$ Corte Suprema, 5 de diciembre de 2013, rol ํ 10115-2013.
} 


\section{Validez temporal del peritaje}

En cuanto a su validez temporal, ha sido la Corte Suprema la encargada de sostener que el peritaje realizado en fecha anterior al rechazo de las licencias médicas objetadas es feble, "motivo por el cual difícilmente pueden dar cuenta del estado de salud de la recurrente a la época señalada" (considerando séptimo). ${ }^{100}$ El reposo del recurrente inició el año 2017, y los peritajes practicados son de 2015 y 2016. Lisa y llanamente estas "medidas para mejor resolver" no brindaban ninguna utilidad práctica, por su evidente desfase temporal.

En una idea semejante, la Corte de Apelaciones de Concepción afirmó que, "el sostener que un peritaje psiquiátrico realizado para una realidad médica ocurrida el 13 de enero de 2016 tenga validez para otra acaecida el 30 de marzo de 2016 carece de todo sustento médico, por cuanto en el decurso de 2 meses, entre una y otra realidad, pueden desencadenarse diversas situaciones no consideradas en el peritaje en que las recurridas fundan el rechazo de la licencia médica en comento, desfasado en el tiempo" (considerando 16). ${ }^{101}$ Pero esta sentencia fue revocada por la Corte Suprema. ${ }^{102}$

Y la Corte de Apelaciones de Temuco declaró infundado el rechazo de licencias médicas, entre otras razones, por no haberse practicado un nuevo peritaje que permitiera determinar si el recurrente mantenía o no su padecimiento (considerando octavo). En este caso, se había practicado un peritaje en fecha anterior, el que fue considerado en el rechazo a pesar del tiempo transcurrido. ${ }^{103}$

Del estudio de estas resoluciones, podemos asumir que los peritajes médicos pueden ser comparados con una fotografía: sólo evidencian lo existente al momento de su práctica, y no más que ello; siendo especulativo lo que pueda afirmarse a futuro en virtud de la información proporcionada por el peritaje.

Pero una postura contraria sostuvo la Corte penquista cuando asentó que "no existe alguna disposición legal o reglamentaria que desacredite

\footnotetext{
${ }^{100}$ Corte Suprema, 10 de mayo de 2018, rol N 841-2018.

101 Corte de Apelaciones de Concepción, 22 de agosto de 2016, rol N 11039-2016, de recursos civil.

102 Corte Suprema, 26 de octubre de 2016, rol N 65350-2016.

103 Corte de Apelaciones de Temuco, 20 de julio de 2018, rol N 1804-2018, protección (confirmada por Corte Suprema, 22 de octubre de 2018, rol N 18864-2018).
} 
un peritaje realizado con anterioridad, esto es, no coetáneo a la licencia médica reclamada" (considerando $\left.9^{\circ}\right) .{ }^{104} \mathrm{El}$ mismo tribunal expuso en otra sentencia que, "en este contexto, no puede pretenderse por la recurrente que por haberse practicado el aludido examen médico respecto a una licencia anterior a la que motiva la presente acción de protección resulte inaplicable a la situación de esta nueva licencia, máxime si no se han aportado otros antecedentes que justifiquen una variación en la situación de salud de la actora" (considerando sexto). ${ }^{105}$

En un punto relacionado, este tribunal declaró justificado el rechazo de las licencias, fundado en que, "por estar en presencia de licencias continuadas, la pericia psiquiátrica posee por sí sola el mérito suficiente para justificar el rechazo de todas las licencias médicas impugnadas" (considerando $4^{\circ}$ ). En este caso, un peritaje declaró justificado el reposo hasta cierta fecha de la primera licencia, rechazando el prescrito para el resto del plazo fijado en ella y en las que le sucedieron. El mismo fallo agrega que no se acompañó prueba alguna para desvirtuar el valor del peritaje (considerando $\left.3^{\circ}\right) .{ }^{106}$

En otra sentencia, este tribunal de alzada, amparándose en la potestad de la COMPIN, la Unidad de Licencias Médicas y las ISAPRE para pronunciarse sobre las licencias médicas, estimó que la norma no les exige que el peritaje que practiquen sea contemporáneo al pronunciamiento, ni que deba realizarse uno por cada rechazo (considerando $\left.16^{\circ}\right) .^{107}$

\section{Imparcialidad de quien practica el peritaje}

Bajo este epígrafe pretendemos determinar si el peritaje médico practicado a instancia de la COMPIN o de una ISAPRE tiene valor, debido a que podría existir algún conflicto de interés o de subordinación entre el profesional encargado de la diligencia y el mandante. Esta circunstancia se hace más notoria cuando quien pide el peritaje es una ISAPRE, la que, dicho sea de paso, financia su práctica o es el empleador del perito.

\footnotetext{
104 Corte de Apelaciones de Concepción, 22 de agosto de 2016, rol № 9356-2016, de recursos civil. Así también, Corte de Apelaciones de Concepción, 28 de septiembre de 2016, rol № 18626-2016, de recursos civil; Corte de Apelaciones de Concepción, 24 de agosto de 2015, rol º 4616-2015, de recursos civil; y Corte Suprema, 26 de octubre de 2016, rol N 65350-2016.

105 Corte de Apelaciones de Concepción, 28 de septiembre de 2016, rol N 18626-2016, de recursos civil.

106 Corte de Apelaciones de Concepción, 23 de febrero de 2018, rol º 290-2018, protección.

107 Corte de Apelaciones de Concepción, 30 de abril de 2014, rol N 1709-2014, de recursos civil.
} 
Es así que la Corte Suprema estimó que hay un acto ilegal si la pericia es realizada por un médico interconsultor de la misma ISAPRE que rechazó la licencia médica, pues perdió su condición de imparcial (considerando séptimo). ${ }^{108}$ En consecuencia, debe entenderse que, aquí, la imparcialidad del profesional es imperativa.

Y respecto del dependiente de la Compin, la Corte de Apelaciones de Concepción concluyó que "el dictamen del perito médico funcionario del organismo recurrido (...) cuenta con el debido fundamento expedido por personero en ejercicio legítimo de su ciencia o arte, constitutivo, a la par, de apoyo de un acto de acto administrativo ejecutado en los términos del artículo $3^{\circ}$ de la antes citada ley 19.880, que goza de presunción de legalidad, de imperio y de exigibilidad, conforme a lo dispuesto en el inciso final de la misma disposición; y, adicionalmente, dotado de imparcialidad, de acuerdo con su artículo 11" (considerando octavo). ${ }^{109}$ De modo que la "imparcialidad" que podría ser a todas luces evidente, desaparece por un conjunto de disposiciones legales.

\section{La mención a la práctica del peritaje}

Respecto a este capítulo, la Corte de Apelaciones de Antofagasta consideró que la mención, en el rechazo, de la práctica de un peritaje médico prueba la existencia de una fundamentación suficiente, "puesto que si bien no se trata de un trámite que esté expresamente regulado en la normativa sectorial, constituye un claro esfuerzo del organismo de salud por incorporar fundamentación a su decisión para no autorizar esta licencia médica" (considerando séptimo). ${ }^{110}$ La Corte de Apelaciones de Chillán estimó fundado la actuación de la compin confirmando el rechazo de las licencias médicas por parte de una ISAPRE, que se basó para ello en un peritaje, el cual afirma que no se justificada el reposo prescrito (considerando $9^{\circ}$ ). ${ }^{11}$ En un sentido semejante falló la Corte de Apelaciones de Concepción, exponiendo que el acto que rechaza una licencia aduciendo los resultados de un peritaje

\footnotetext{
108 Corte Suprema, 21 de agosto de 2017, rol N 19166-2017.

109 Corte de Apelaciones de Concepción, 25 de octubre de 2013, rol № 12958-2013, de recursos civil. 110 Corte de Apelaciones de Antofagasta, 12 de agosto de 2016, rol № 2515-2016, protección. En semejante sentido, Corte de Apelaciones de Concepción, 22 de agosto de 2016, rol № 9356-2016, de recursos civil.

${ }^{111}$ Corte de Apelaciones de Chillán, 5 de septiembre de 2011, rol No 103-2011, civil.
} 
es fundado, aunque el texto sea breve, pues "no significa en este caso una ausencia de expresión de las razones que sustentan la decisión que se reprocha y que, por ende, adolezca de ilegalidad el acto de que se trata". ${ }^{112}$

La Corte Suprema emitió un fallo controvertido cuando declaró ajustado a Derecho el rechazo de licencias médicas en virtud de un informe médico realizado por profesionales de la recurrida SUSESo, pues no se le pudo realizar un peritaje al recurrente por carecer la contraria de médicos en la Región respectiva (considerando cuarto). ${ }^{113}$ Lo interesante del informe es que, como señala el voto de minoría, fue invocado por la SUSESO como "peritaje", lo cual resulta ser falso: el documento en cuestión era un informe protocolizado escrito a mano (punto 3 del voto de minoría). ${ }^{114}$

\section{EL PRONUNCIAMIENTO DEBE BASTARSE A SÍ MISMO}

Hemos querido dejar para el final una sentencia dictada por la Corte de Apelaciones de Concepción. Su importancia no está en el hecho de declarar legal un rechazo de licencia médica, sino porque entiende que un pronunciamiento negativo puede estar debidamente fundado o motivado aun cuando no se baste a sí mismo. O, en otras palabras, cuando sea imprescindible, para entender por qué la entidad respectiva dictaminó en un sentido determinado, estarse más al expediente administrativo que al pronunciamiento en sí.

De esta manera, expuso que, "luego del examen de los antecedentes, particularmente de la Resolución impugnada y del expediente administrativo que fuera allegado por los recurridos, se advierte que la falta de fundamentación que el recurrente reprocha al acto impugnado resulta del todo ajena a la realidad. En efecto, puede observase que la decisión de rechazo de las licencias médicas consultas se basa en un peritaje practicado por un facultativo del área, que explica razonadamente porqué el descanso laboral que sugieren las licencias médicas (...) no resulta atendible luego de un descanso previo de cuatro meses", y "que, aun cuando la Resolución impugnada contiene deficiencias formales, ello no afecta su acertada

112 Corte de Apelaciones de Concepción, 9 de septiembre de 2013, rol No 3940-2013, de recursos civil. En un sentido semejante, Corte de Apelaciones de Concepción, 22 de agosto de 2018, rol N 6582-2018, protección.

113 Corte Suprema, 3 de abril de 2017, rol No 87902-2016.

114 Ídem, voto de minoría. 
inteligencia, así como tampoco le resta fundamentación, lo que además fue aclarado en estos autos con los antecedentes que proporciona el Expediente Administrativo y principalmente, el Peritaje que antecedió y motivó la decisión del ente administrativo" (las cursivas son nuestras, considerandos cuarto y quinto). ${ }^{115}$

Es evidente que el tribunal reconoce que el pronunciamiento emitido es deficiente en cuanto a su forma; pero que su fundamentación fue aclarada por lo que consta en el expediente administrativo. Según ya dijimos, Bermúdez entiende que la exposición de las razones en el acto administrativo puede ser sucinta, pero ello no implica, a nuestro juicio, que llegue al extremo de tener que recurrir a un expediente administrativo para saber por qué se resolvió en tal o cual sentido. Los actos administrativos y, en general, los pronunciamientos recaídos sobre las licencias médicas deben bastarse a sí mismo. O sea, deben tener una fundamentación o motivación tal que cualquiera que los lea pueda entender por qué se dictó.

Esta exigencia no solo se sustenta en la existencia de textos legales, sino también en razones superiores: una licencia médica rechazada provoca efectos patrimoniales, médicos y contractuales, tanto para el trabajador como para terceros; y es imprescindible poder tener conocimiento absoluto y completo de esas razones para adoptar las medidas médicas y jurídicas necesarias para revisar o revertir la decisión adoptada.

El rechazo de una licencia médica debe ser debidamente fundado al momento de emitirse el pronunciamiento, no después, y mucho menos por medio de un informe emitido durante un recurso de protección. Seguir una idea contraria atenta contra las bases del Estado de Derecho.

El rechazo debe estar redactado en términos suficientes como para que cualquiera que lo lea lo entienda sin necesidad de recurrir a otras fuentes.

Y para finalizar, se puede cuestionar si el rechazo fue bien o no decretado; pero nunca se puede dudar de si se dieron o no razones para adoptar tamaña decisión.

\section{A MODO DE CONCLUSIÓN}

De estas resoluciones judiciales y administrativos, podemos extraer un conjunto de valiosas conclusiones para determinar el estándar de fundamentación objeto de este estudio:

115 Corte de Apelaciones de Concepción, 22 de agosto de 2018, rol N 6582-2018, protección. 
$1^{\circ}$. Todo pronunciamiento debe ser emitido por un médico-cirujano que posea idénticas o superiores competencias o especialidades que aquel que emitió la licencia médica. Lo ideal sería que las licencias médicas dadas por cirujanos-dentistas o por matronas no deban ser resueltas por médicoscirujanos.

$2^{\mathrm{o}}$. Todo pronunciamiento de rechazo (y todo recurso administrativo recaído sobre aquél) por causales de orden médico debe ser redactado en términos claros y precisos, empleando, en lo posible, expresiones de uso común. La referencia a textos legales o reglamentarios o expresiones técnicas o de otro carácter debe incluirse a condición de que exista una explicación para ello o desarrollando su contenido. Las expresiones médicas deben ser usadas con cautela.

En el texto del rechazo (y del recurso) no pueden emplearse frases cliché, de estilo o vacías, sin darles un contenido o un desarrollo argumentativo. Por lo mismo, conformarse con anotar en el formulario que no se probó la incapacidad laboral, que el informe médico aportado no permite probar incapacidad, o que el reposo es injustificado o hay salud irrecuperable, importa una manifiesta falta de fundamentación o motivación. Contrario a lo que Bermúdez afirma, la precisión del argumento, aquí, es una exigencia inexcusable, atendidas las consecuencias que el rechazo de la licencia médica importa. Lo dicho se ajusta, además, a lo que la SUSESO ha sustentado; ${ }^{116}$ en particular cuando recalca que el pronunciamiento debe bastarse a sí mismo. ${ }^{117}$ Ello también concuerda con el deber de eficiencia y eficacia de la Administración.

Los informes médicos y exámenes practicados deben individualizarse con la debida precisión, y su contenido debe desglosarse de forma tal de saber por qué son tenidos en cuenta al momento del pronunciamiento. Esto mismo rige para los demás antecedentes complementarios que se tengan a la vista al momento de emitir el pronunciamiento.

Tanto las reglas de Derecho como las técnicas de las ciencias médicas deben ser expresadas con la debida coherencia, sin que entre ellas exista contradicción.

$3^{\circ}$. Todo diagnóstico o prognosis emitido por un profesional de la salud debe tenerse por cierto y efectivo, mientras no sea impugnado o cuestionada por quien debe emitir el pronunciamiento, correspondiendo a

\footnotetext{
116 Suseso, Circular $N^{\circ} 1588$, 1997, punto IV, 1; y Circular $N^{\circ} 2067,2005$, punto I.3.q).

117 SusEso, Circular No 2067, 2003, punto I.
} 
quien lo objeta o lo coloca en duda acreditar lo que afirma. Este postulado concuerda con la carga de la Administración (y de la ISAPRE) de probar lo que sustenta. En especial, debe tenerse por cierto y efectivo si la patología está comprendida en las "Guías Clínicas Referenciales", siempre que la licencia fue otorgada por el profesional que ellas mencionan y con los exámenes e informes correspondientes, por cuanto la decisión del profesional no solo se ajusta a la lex artis médica, sino que, también, a lo prescrito por un texto reglamentario expreso y vigente.

$4^{\text {}}$. Si quien debe pronunciarse sobre la licencia médica (o el recurso administrativo) tuviere dudas sobre el reposo prescrito o necesita mayores antecedentes para resolver, debe ejercer las potestades que el Reglamento le confiere en este sentido. Fallar sin ejercerlas constituye falta de motivación o fundamentación. Esta exigencia concuerda con la carga de la Administración y de la ISAPRE de probar lo que afirma.

$5^{\circ}$. Contribuye a la fundamentación las resoluciones emitidas por otros órganos de la Administración del Estado o alguna entidad competente; pero no resulta conveniente sostener el pronunciamiento única y exclusivamente en ellas, si existen otros antecedentes (que se encuentren a mano u obtenibles mediante un peritaje) que permitan sustentar una postura contraria o, por lo menos, pongan en tela de juicio aquella resolución.

$6^{\circ}$. La causal de rechazo consistente en salud irrecuperable debe basarse en circunstancias graves, con antecedentes concretos, precisos y comprobables. La mera referencia a plazos de duración del reposo o a cualquier otro elemento especulativo debe ser descartada de plano. Y, por sobre todo, se debe tener presente lo que la propia SUSESO ha entendido respecto de las enfermedades crónicas o irrecuperables.

$7^{\circ}$. La declaración de invalidez, o su rechazo, no constituyen per se argumentos para rechazar una licencia médica por salud irrecuperable.

$8^{\circ}$. Los peritajes médicos siempre deben ser decretados si fueran necesarios para mejor resolver. En particular, si se pretende desvirtuar lo afirmado por el profesional tratante. Recordemos que, mientras no sea probado lo contrario, lo que él señale debe tenerse por cierto. No actuar así hace que el pronunciamiento no esté debidamente fundado o motivado.

$9^{\circ}$. Aunque los peritajes médicos son valiosos para resolver, no se les puede dar valor de plena prueba: deben ser apreciados en su justa medida, sin perjuicio del derecho de la parte interesada de impugnarlos.

10. Los peritajes médicos solo tienen validez respecto de los hechos verificados a la fecha de su emisión. Cualquier pronóstico que ellos expongan 
o que se puedan extraer de su contenido es especulativo, aun cuando se sustente en la lex artis médica. De ser posible, se practicarán tantos peritajes cuantas licencias médicas se extiendan a favor de una persona.

11. El peritaje ordenado por una ISAPRE y practicado por uno de sus dependientes, carece de validez probatoria, pues el profesional no posee la debida imparcialidad. Lo recién expuesto no tiene lugar cuando el peritaje es ordenado por un órgano de la Administración del Estado y, quien lo realiza es un funcionario público.

\section{BIBLIOGRAFÍA CITADA}

\section{A) Doctrina}

AlEXy, Robert, Teoría de la argumentación jurídica. La teoría del discurso racional como teoría de la fundamentación jurídica, Palestra, Lima, 2016.

Atienza, Manuel, Las razones de Derecho. Teorías de la argumentación jurídica, Universidad Nacional Autónoma de México, Instituto de Investigaciones Jurídicas, México, 2017.

Bermúdez Soto, Jorge, Derecho Administrativo general, Thomson Reuters, Santiago, 2014, $3^{\mathrm{a}}$ ed. actualizada.

Besio, Mauricio, "La licencia médica. Varias dimensiones en un mismo documento. Una propuesta para un mejor uso", Revista Médica de Chile, 2001, Vol. 139, $\mathrm{N}^{\circ} 11$, pp. 1503-1507.

Biblioteca del Congreso Nacional, "Historia de la Ley No 20.585, Sobre Otorgamiento y Uso de Licencias Médicas", documento pdf. disponible en línea: https://www.bcn.cl/historiadelaley/fileadmin/file_ley/4426/Pdf/Dossier/ HLD_4426_dossierd10ee3d1e00de59cfdd6070e831cc33d.pdf, (consultado al 30 de mayo de 2019).

Celis Danzinger, Gabriel, Curso de Derecho Administrativo, Thomson Reuters - PuntoLex, Santiago, 2010, T. I.

Cordero Vega, Luis, Lecciones de Derecho Administrativo, Thomson Reuters, Santiago, 2015, $2^{\mathrm{a}}$ ed. corregida.

Garrido Montt, Mario, Derecho Penal. Parte especial, Editorial Jurídica de Chile, Santiago, 2010, $4^{a}$ edición actualizada, T. III.

Gordillo, Agustín, Tratado de Derecho Administrativo, Fundación de Derecho Administrativo, Buenos Aires, 2011, 10ª edición, T. 3.

Ministerio de Salud (eds.), Compendio de Normas Administrativas en Materia de Procedimientos, Gobierno de Chile, Superintendencia de Salud, Santiago, 2012, 427 pp., archivo pdf. disponible en línea: http://www.supersalud. 
gob.cl/normativa/668/articles-6678_recurso_1.pdf.

Moraga Klenner, Claudio, "Notas al procedimiento administrativo y la doctrina chilena", en Pantoja Bauzá, R. (coord.), Derecho Administrativo. 150 años de doctrina, Editorial Jurídica de Chile, Santiago, 2009.

Politoff L., Sergio; Matus A., Jean Pierre; Ramírez G, María Cecilia, Lecciones de Derecho Penal chileno. Parte especial, Editorial Jurídica de Chile, Santiago, 2005, 2a edición.

Sото KLoss, Eduardo, Derecho Administrativo. Temas fundamentales, Abeledo Perrot - LegalPublishing, Santiago, 2012, $3^{\text {a }}$ ed. actualizada.

Superintendencia de Seguridad Social, "Estadísticas nacionales de LM y SIL 2017", documento disponible en línea: https:/www.suseso.cl/608/w3article-577871.html (visitada al 30 de mayo de 2019).

B) Normativa:

Decreto $\mathrm{N}^{\circ} 3$, de 1984.

Ley $\mathrm{N}^{\circ} 19.880$, de 2003.

Decreto con Fuerza de Ley $\mathrm{N}^{\circ}$ 1, 2006.

Ley $\mathrm{N}^{\circ} 20.581$, de 2012.

Circular $\mathrm{N}^{\circ} 1588$, de 1997.

Circular $N^{\circ} 2067$, de 2003.

Circular $\mathrm{N}^{\circ} 2434$, de 2008.

Circular B10/N 15 , de 2018.

Ley N²7.444, de 2001 (Perú).

\section{C) Jurisprudencia judicial:}

Corte de Apelaciones de Temuco, 22 de abril de 1999, R.D.J. T. 96, sec. 5, p. 161 .

Corte de Apelaciones de Santiago, 3 de noviembre de 2009, rol N ${ }^{\circ} 767-$ 2009, protección.

Corte de Apelaciones de Valparaíso, 3 de junio de 2010, rol $\mathrm{N}^{\circ}$ 185-2010, protección. civil.

Corte de Apelaciones de Chillán, 5 de septiembre de 2011, rol N 103-2011,

Corte de Apelaciones de Concepción, 22 de marzo de 2012, rol 185-2012, civil.

Corte de Apelaciones de Concepción, 30 de julio de 2012, rol № 1349-2012, civil. 
Corte de Apelaciones de Temuco, 11 de diciembre de 2012, rol 2016-2012, protección.

Corte de Apelaciones de Concepción, 21 de septiembre de 2012, rol N ${ }^{\circ}$ 1745-2012, civil.

Corte de Apelaciones de Concepción, 24 de septiembre de 2012, rol $\mathrm{N}^{\circ}$ 1667-2012, civil.

Corte Suprema, 5 de diciembre de 2013, rol N 10115-2013.

Corte de Apelaciones de Concepción, 9 de septiembre de 2013, rol № 39402013, de recursos civil.

Corte de Apelaciones de Concepción, 25 de octubre de 2013, rol No 12958 2013, de recursos civil.

Corte de Apelaciones de Concepción, 30 de abril de 2014, rol No 1709-2014, de recursos civil.

Corte de Apelaciones de Concepción, 8 de julio de 2014, rol 2349-2014, de recursos civil.

Corte de Apelaciones de Concepción, 24 de agosto de 2015, rol ํ ${ }^{\circ 616-}$ 2015, de recursos civil.

Corte de Apelaciones de Concepción, 7 de marzo de 2016, rol N 420-2016, de recursos civil.

Corte de Apelaciones de Antofagasta, 12 de agosto de 2016, rol № 25152016, protección.

Corte de Apelaciones de Concepción, 22 de agosto de 2016, rol № 93562016, de recursos civil.

Corte de Apelaciones de Concepción, 22 de agosto de 2016, rol № 110392016, de recursos civil.

Corte de Apelaciones de Concepción, 28 de septiembre de 2016, rol N ${ }^{\circ}$ 18626-2016, de recursos civil.

Corte de Apelaciones de Concepción, 6 de octubre de 2016, rol No $19013-$ 2016, de recursos civil. civil.

Corte de Apelaciones de La Serena, 6 de octubre de 2016, rol No 1547-2016,

Corte de Apelaciones de Santiago, 18 de octubre de 2016, rol № 100008 2016, protección.

Corte Suprema, 26 de octubre de 2016, rol N 65350-2016.

Corte de Apelaciones de Puerto Montt, 18 de noviembre de 2016, rol N ${ }^{\circ}$ 2394-2016, protección.

Corte Suprema, 24 de noviembre de 2016, rol No 58877-2016.

Corte de Apelaciones de Santiago, 11 de enero de 2017, rol No 118499-2016, protección.

Corte de Apelaciones de Concepción, 23 de marzo de 2017, rol № 4192017, de recursos civil. 
Corte de Apelaciones de Puerto Montt, 24 de marzo de 2017, rol No 154 2017, protección.

Corte Suprema, 30 de marzo de 2017, rol No 87815-2016.

Corte de Apelaciones de Concepción, 6 de abril de 2017, rol No 328-2017, de recursos civil.

Corte Suprema, 3 de abril de 2017, rol No 87902-2016.

Corte Suprema, 11 de abril de 2017, rol No 309-2017.

Corte Suprema, 25 de abril de 2017, rol N³8151-2016.

Corte Suprema, 18 de mayo de 2017, rol No 10406-2017.

Corte de Apelaciones de Concepción, 28 de junio de 2017, rol No 32982017, de recursos civil.

Corte de Apelaciones de Temuco, 4 de agosto de 2017, rol № 2982-2017, protección.

Corte Suprema, 21 de agosto de 2017, rol N 19166-2017.

Corte de Apelaciones de Temuco, 7 de septiembre de 2017, rol $\mathrm{N}^{\circ} 2668$ 2017, protección.

Corte Suprema, 14 de noviembre de 2017, rol No 35289-2017.

Corte Suprema, 11 de enero de 2018, rol N 40188-2017.

Corte Suprema, 19 de febrero de 2018, rol N 39714-2017.

Corte Suprema, 19 de febrero de 2018, rol No 41367-2017.

Corte de Apelaciones de Concepción, 23 de febrero de 2018, rol № 2902018, protección.

Corte Suprema, 5 de marzo de 2018, rol No 31-2018.

Corte de Apelaciones de Concepción, 7 de marzo de 2018, rol N 85062017, de recursos civil.

Corte Suprema, 10 de mayo de 2018, rol N 841-2018.

Corte de Apelaciones de Temuco, 22 de mayo de 2018, rol N 1437-2018, protección.

Corte Suprema, 19 de junio de 2018, rol ํ $5321-2018$.

Corte de Apelaciones de Temuco, 22 de junio de 2018, rol N 2013-2018, protección.

Corte Suprema, 27 de junio de 2018, rol N 12624-2018.

Corte de Apelaciones de Temuco, 20 de julio de 2018, rol $N^{\circ} 1804-2018$, protección.

Corte de Apelaciones de Concepción, 27 de julio de 2018, rol N 6795-2018, protección.

Corte de Apelaciones de Temuco, 16 de agosto de 2018, rol º 2766-2018, protección.

Corte de Apelaciones de Concepción, 17 de agosto de 2018, rol № 51042018 protección.

Corte de Apelaciones de Concepción, 22 de agosto de 2018, rol № 6582- 
2018, protección.

Corte de Apelaciones de Concepción, 27 de agosto de 2018, rol № 59322018, protección.

Corte de Apelaciones de Concepción, 28 de agosto de 2018, rol № 6765 2018, protección.

Corte Suprema, 22 de octubre de 2018, rol N 18864-2018.

Corte Suprema, 30 de octubre de 2018, rol No 22185-2018.

Corte Suprema, 8 de noviembre de 2018, rol N ${ }^{\circ} 15124-2018$.

Corte Suprema, 24 de diciembre de 2018, rol N N$^{\circ} 23244-2018$.

Corte Suprema, 26 de noviembre de 2018, rol N ${ }^{\circ} 19005-2018$.

Corte Suprema, 24 de diciembre de 2018, rol N N $^{\circ} 23244-2018$.

\section{D) Jurisprudencia administrativa:}

Contraloría General de la República, Dictamen N 94157, 4 de diciembre de 2014, disponible en www.contraloria.cl.

Suseso, Dictamen N 1731,17 de enero de 2001.

SusEso, Dictamen 7528, 7 de marzo de 2001.

Suseso, Dictamen 4918, 1 de febrero de 2002.

Suseso, Dictamen 4872, 1 de febrero de 2003.

Suseso, Dictamen 624, 7 de enero de 2005.

SusESO, Dictamen 62111, 24 de noviembre de 2006.

Suseso, Dictamen 8893, 9 de febrero de 2007.

Suseso, Dictamen 36882, 8 de junio de 2007.

Suseso, Dictamen 21874, 31 de marzo de 2008.

SusEso, Dictamen 47623, 15 de julio de 2008.

Suseso, Dictamen 62952, 7 de octubre de 2008.

SusESO, Dictamen 51781, 19 de octubre de 2009.

Suseso, Dictamen 68078, 28 de diciembre de 2009.

SusESo, Dictamen 1251, 8 de enero de 2010.

SusESo, Dictamen 1851, 12 de enero de 2010.

SusEso, Dictamen 1865, 12 de enero de 2010.

Suseso, Dictamen 9117, 15 de febrero de 2010.

Suseso, Dictamen 9611, 18 de febrero de 2010.

Suseso, Dictamen 10815, 24 de febrero de 2010.

SusESo, Dictamen 10820, 24 de febrero de 2010.

SusESo, Dictamen 11662, 4 de marzo de 2010.

Suseso, Dictamen 12957, 10 de marzo de 2010.

Suseso, Dictamen 17484, 26 de marzo de 2010.

SusESO, Dictamen 20023, 7 de abril de 2010. 
Suseso, Dictamen 27585, 6 de mayo de 2010.

Suseso, Dictamen 53789, 24 de agosto de 2010.

Suseso, Dictamen 56081, 14 de septiembre de 2011.

Suseso, Dictamen 254, 3 de enero de 2012.

Suseso, Dictamen 255, 3 de enero de 2012.

Suseso, Dictamen 9503, 9 de febrero de 2012.

Suseso, Dictamen 35751, 6 de junio de 2012.

Suseso, Dictamen 38215, 15 de junio de 2012.

Suseso, Dictamen 30875, 17 de mayo de 2013.

SusEso, Dictamen 70675, 8 de noviembre de 2013.

Suseso, Dictamen 76296, 13 de diciembre de 2013.

Suseso, Dictamen 51003, 6 de agosto de 2014.

Suseso, Dictamen 68237, 15 de agosto de 2014.

Suseso, Dictamen 69055, 30 de noviembre de 2015.

Suseso, Dictamen 6132, 2 de febrero de 2016.

Suseso, Dictamen 17132, 19 de junio de 2018.

SusEso, Dictamen 19393, 5 de julio de 2018. 